WALDEN

UNIVERSITY

A higher degree. A higher purpose.

Walden University

ScholarWorks

\title{
Care coordination, family-centered care and functional ability in children with special health care needs in the United States
}

Madeline Marti-Morales

Walden University

Follow this and additional works at: https://scholarworks.waldenu.edu/dissertations

Part of the Health and Medical Administration Commons, and the Public Health Education and Promotion Commons

This Dissertation is brought to you for free and open access by the Walden Dissertations and Doctoral Studies Collection at ScholarWorks. It has been accepted for inclusion in Walden Dissertations and Doctoral Studies by an authorized administrator of ScholarWorks. For more information, please contact ScholarWorks@waldenu.edu. 


\title{
Walden University
}

COLLEGE OF HEALTH SCIENCES

This is to certify that the doctoral dissertation by

\author{
Madeline Marti-Morales
}

has been found to be complete and satisfactory in all respects, and that any and all revisions required by the review committee have been made.

\section{Review Committee}

Dr. James Rohrer, Committee Chairperson, Public Health Faculty Dr. William Barkley, Committee Member, Public Health Faculty Dr. Angela Prehn, Committee Member, Public Health Faculty Dr. Amany Refaat, University Reviewer, Public Health Faculty

Chief Academic Officer

David Clinefelter, Ph.D.

Walden University

2011 


\begin{abstract}
Care Coordination, Family-Centered Care and Functional Ability in Children with Special Health Care Needs in the United States

by

Madeline Marti-Morales
\end{abstract}

MS, University of Puerto Rico, 2002

BS, University of Puerto Rico, 1996
Dissertation Submitted in Partial Fulfillment
of the Requirements for the Degree of
Doctor of Philosophy

Public Health

Walden University

May 2011 


\begin{abstract}
Children with special health care needs (CSHCN) generally have physical, mental, or emotional conditions that require a broader range and greater quantity of health and related services compared to typical children. Care coordination (CC) and familycentered care (FCC) are necessary in the quality of health care for CSHCN. A gap exists in the literature regarding the impact of $\mathrm{CC}$ and $\mathrm{FCC}$ on children's functional ability (FA). Previous researchers have focused on met and unmet health care needs, but not on health outcomes or functionality. The purpose of this study was to determine if there was an association between $\mathrm{CC}, \mathrm{FCC}$, and FA in CSHCN. The design of this study was a secondary analysis of data from the 2005-2006 National Survey of CSHCN. The study was guided by an adapted socioecological multilevel conceptual framework. Statistical methods included univariate, bivariate, and multiple logistic regression analysis. Results indicated that $\mathrm{CC}$ was associated with $\mathrm{FA}$ in $\mathrm{CSHCN}$. $\mathrm{CSHCN}$ that did not receive $\mathrm{CC}$ had a $53 \%$ increased risk $(\mathrm{OR}=1.53,95 \% \mathrm{CI} 1.21-1.94, p<0.001)$ for a limitation in FA compared to $\mathrm{CSHCN}$ that received $\mathrm{CC}$, controlling for age, gender, number of conditions, household poverty level, parental educational level, and health insurance. FCC was not associated with a limitation in FA in $\mathrm{CSHCN}(p=0.61)$. Findings from this study were consistent with the socioecological multilevel framework and the literature on care coordination. This study contributed to positive social change by providing information that can be used by public health officials, health care providers and policy makers in developing policies to assure that care coordination is provided to $\mathrm{CSHCN}$ and their families in order to improve their health outcomes and functionality.
\end{abstract}



Care Coordination, Family-Centered Care and Functional Ability in Children with Special Health Care Needs in the United States

by

Madeline Marti-Morales

MS, University of Puerto Rico, 2002

BS, University of Puerto Rico, 1996

Dissertation Submitted in Partial Fulfillment

of the Requirements for the Degree of

Doctor of Philosophy

Public Health

Epidemiology

Walden University

May 2011 
UMI Number: 3449462

All rights reserved

INFORMATION TO ALL USERS

The quality of this reproduction is dependent upon the quality of the copy submitted.

In the unlikely event that the author did not send a complete manuscript and there are missing pages, these will be noted. Also, if material had to be removed, a note will indicate the deletion.

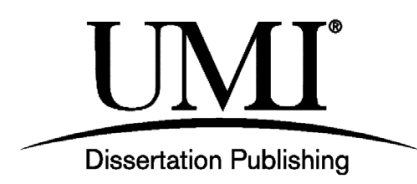

UMI 3449462

Copyright 2011 by ProQuest LLC.

All rights reserved. This edition of the work is protected against unauthorized copying under Title 17, United States Code.

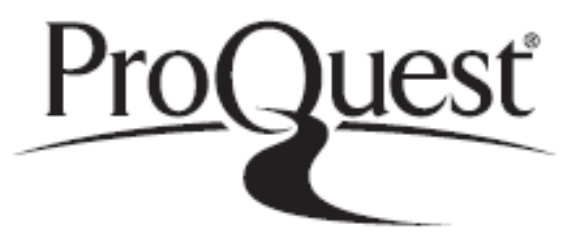

ProQuest LLC

789 East Eisenhower Parkway

P.O. Box 1346

Ann Arbor, Ml 48106-1346 
List of Tables.............................................................

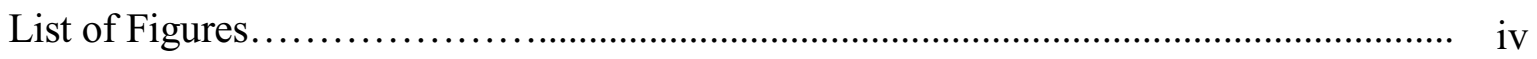

Chapter 1: Introduction to the Study ..................................... 1

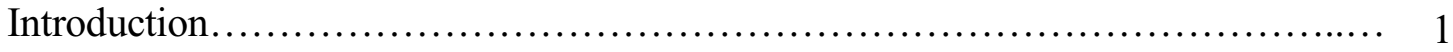

Importance of Care Coordination and Family Centered Care..................... 2

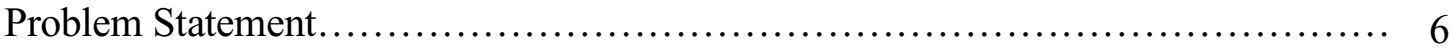

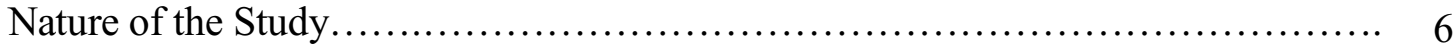

Research Questions and Hypotheses..................................... 7

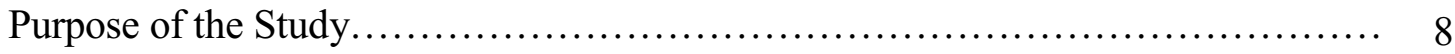

Theoretical Framework............................................................................... 8

Medical, Functional and Social Models of Disability.......................... 8

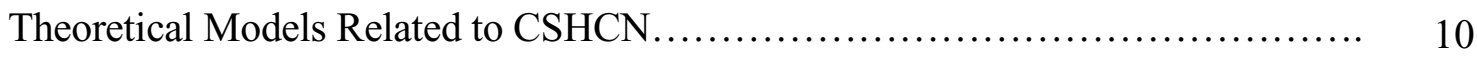

Definition of Terms................................................... 14

Assumptions, Scope of Study and Limitations............................... 15

Significance of Study, including Positive Social Change....................... 16

Summary.......................................................... 16

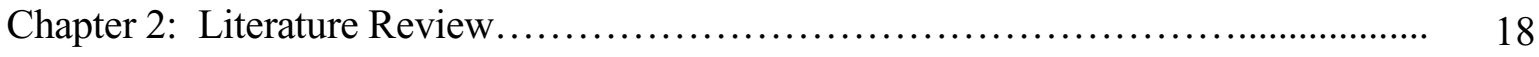

Introduction......................................................... 18

Methods for Retrieving Articles for Literature Review....................... 18

Conceptual Framework....................................................................................... 19

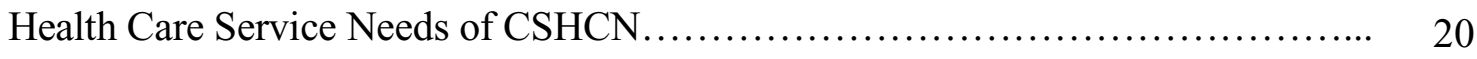

Health Insurance.................................................... 21

CSHCN's Health Care Components...................................... 24

The Medical Home................................................... 24

Care Coordination...................................................... 25

Family-Centered Care................................................... 28

Summary of Methodological Issues...................................... 31

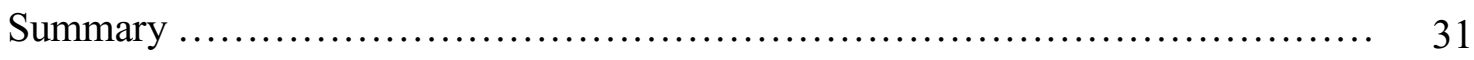

Chapter 3: Research Methods........................................... 34

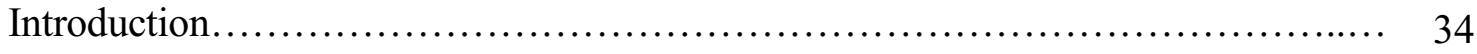

Research Design and Approach......................................... 34 


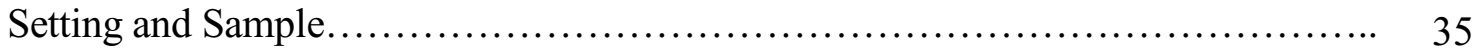

Population and Sample Selection.......................................... 36

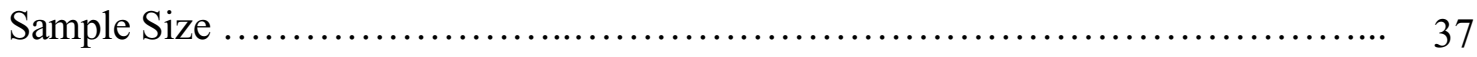

Instrumentation and Materials ................................................. 38

Data Collection Methods............................................... 38

Questionnaire Description................................................ 39

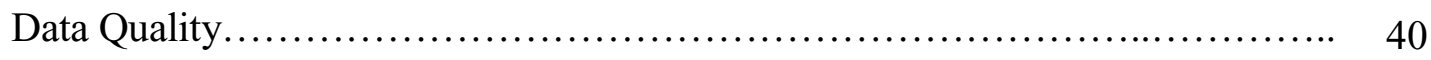

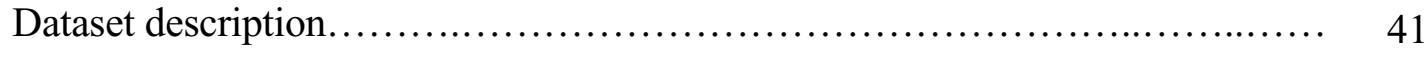

Description of the Study Variables............................................. 41

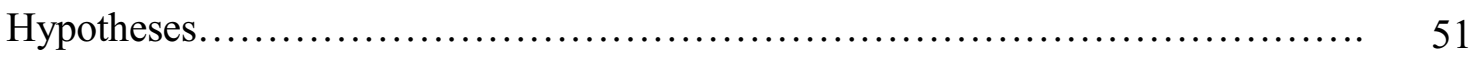

Data Analysis Methods...................................................... 52

Statistical Analysis Software ............................................ 52

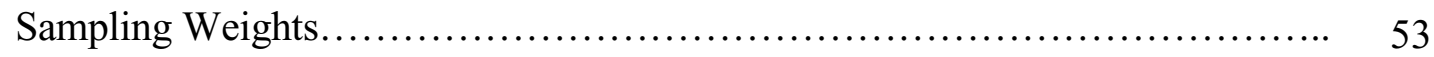

Statistical Analysis Methods............................................ 53

Measures to Protect Participants' Rights...................................... 56

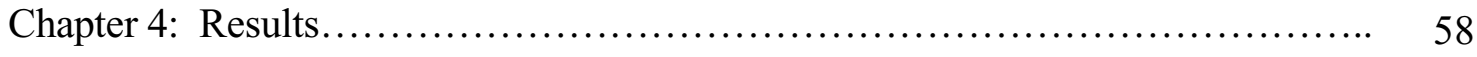

Descriptive Characteristics............................................ 58

Multiple Logistic Regression Analysis for CSHCN in General................... 64

Multiple Logistic Regression Analysis for CSHCN with a Specific Health

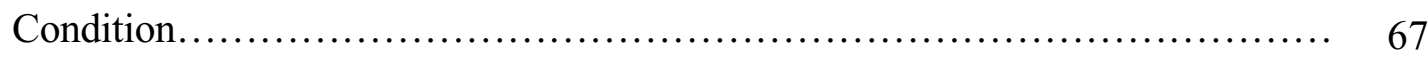

Summary of the Results............................................. 71

Chapter 5: Discussion, Conclusion and Implications for Social Change............. 73

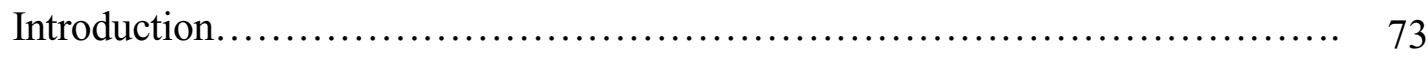

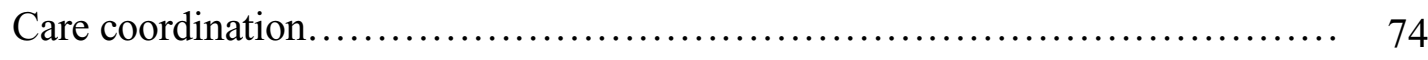

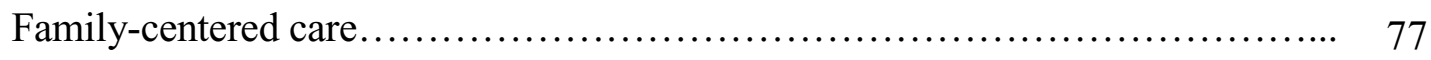

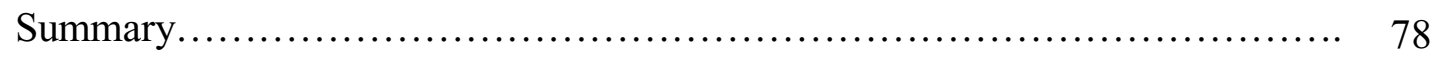

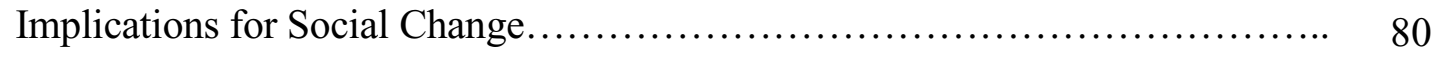

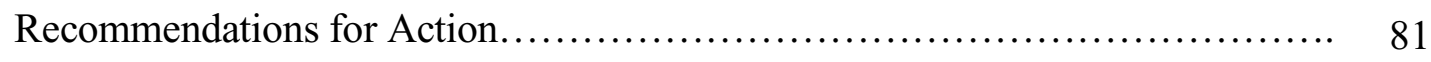

Limitations of the Study ................................................. 81

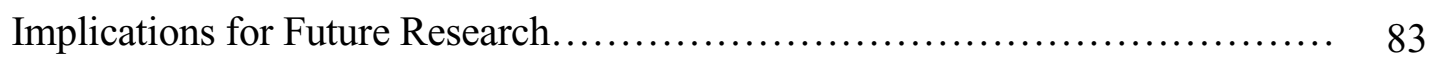

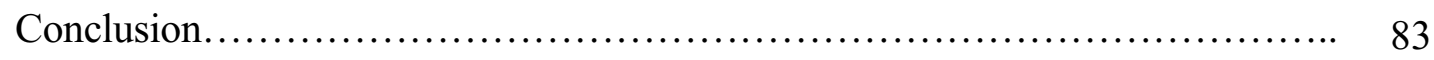

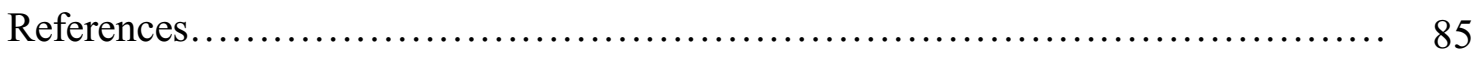

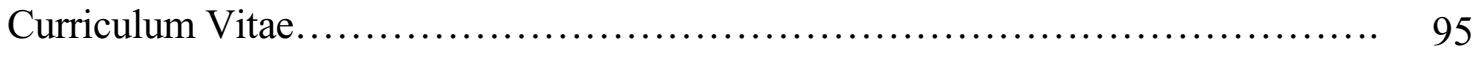




\section{List of Tables}

Table 1. Minimum Sample Size to Test Hypothesis $1 \ldots \ldots \ldots \ldots \ldots \ldots \ldots \ldots \ldots \ldots \ldots \ldots \ldots$

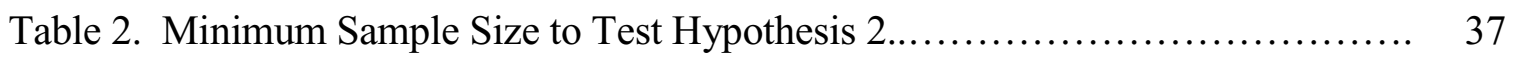

Table 3. Number of Cases by Health Condition................................ 38

Table 4. Specific Care Coordination Questions.............................. 42

Table 5. Algorithm to Combine Care Coordination Questions.................... 45

Table 6. Specific Family-Centered Care Questions............................. 46

Table 7. Algorithm to Combine Family-Centered Care Questions..................... 47

Table 8. Study Variables................................................. 54

Table 9. Percent of CSHCN by Limitation in Functional Ability..................... 59

Table 10. Mean Age of Children with Special Health Care Needs.................. 60

Table 11. Child-Level Characteristics of CSHCN in General and by Limitation

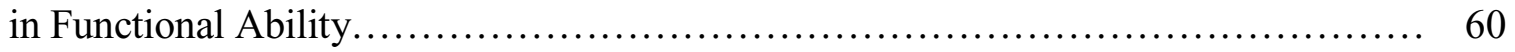

Table 12. Family-Level Characteristics of CSHCN in General and by Limitation in

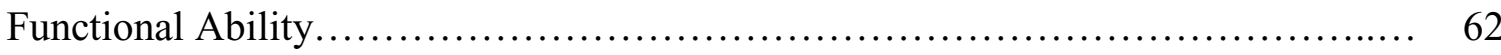

Table 13. Community-Level Characteristics of CSHCN in General and by Limitation in Functional Ability ....................................... 63

Table 14. Multivariate Logistic Regression Models Examining the Relationship between Functional Limitation, Care Coordination, Family-Centered Care

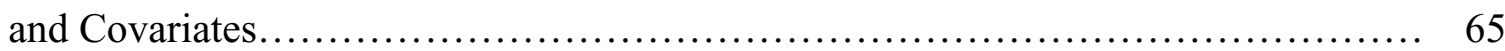

Table 15. Percent of CSHCN with ADD/ADHD and Functional Limitation........... 68 Table 16. Multivariate Logistic Regression of the Relationship between Functional Limitation, Care Coordination, Family-Centered Care and Covariates in CSHCN

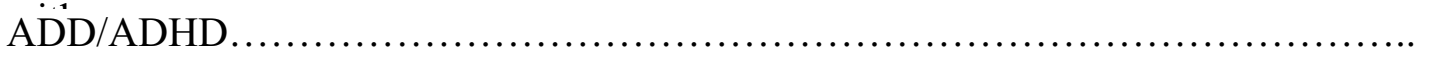




\section{List of Figures}

Figure 1. Diagram that depicts the multilevel variables in relation to children's functionality based on the socioecological model................................. 
Chapter 1: Introduction to the Study

\section{Introduction}

Children with special health care needs $(\mathrm{CSHCN})$ usually require a broad range of services and services in greater quantity than children without special needs in order to improve their health and functionality. CSHCN usually have physical, mental or emotional conditions that have lasted for more than 1 year (Denboba, McPherson, Kenney, Strickland, \& Newacheck, 2006). In recent years, improvements in the survival and life expectancy of CSHCN have been possible due to new discoveries and advances in medicine and public health interventions (Boyle, Decoufle, \& Yeargin-Allsopp, 1994; Newacheck \& Taylor, 1992). For example, the chance of survival for a child with down syndrome has increased from less than $50 \%$ in the 1950 decade to $91 \%$ in the 1990 decade (Lollar \& Crews, 2003).

It is important for public health practitioners to consider people with disabilities in its agenda, especially because they expend considerable medical resources and expenditures. In order to maintain their health, $\mathrm{CSHCN}$ require services that include specialized health services; therapeutic services, including therapies; mental health services; family support services, including care coordination, and respite care; medical supplies and equipment; and other services, including early intervention, transportation, and special education, among others (McPherson, Arango, Fox, Lauver, McManus, Newacheck, Perrin, Shonkoff, \& Strickland, 1998). In addition to requiring more and varied services, CSHCN typically also require prescription medicines for their health conditions. According to Newacheck and Kim (2005), service costs for children with 
special needs are three times higher compared to children without special needs. A child with special needs spent an average of $\$ 2,099$ in health services costs, while children without special needs spent approximately $\$ 628$ in year 2000. Service costs for CSHCN represented an estimated $33.6 \%$ of total health care costs due to their need for services and prescription medications (Newacheck \& Kim, 2005).

It has been estimated that $13.9 \%$ of children had special needs in $2005-2006$ in the United States (DHHS, 2008). The prevalence is higher compared to the estimate obtained from the 2001-2002 National Survey in which $12.8 \%$ of children had special health needs (DHHS, 2004). This increase in CSHCN prevalence has been attributed to a number of factors, including the possible increase in the number of CSHCN, improvements in diagnosis, increased access to health care, and increase in knowledge and awareness by health care professionals and parents about special health conditions and services (DHHS, 2008).

\section{Importance of Care Coordination and Family-Centered Care}

The main goal of the health care system is to improve the health, functionality, and quality of people's health, especially those with chronic health conditions (Eiser \& Moore, 2001). CSHCN often have complex health conditions, limitations, and needs that require services by primary and specialized physicians in managed care organizations and diverse settings. The system of care is composed of multiple settings, organizations, health plans, and services, which requires a comprehensive knowledge of resources offered at all levels, including primary or pediatric care, and educational and community services. Additionally, organizations may have differing eligibility criteria and funds availability. According to Benedict (2006), when CSHCN do not receive services that 
they need their activities and development are affected and tend to have poorer health compared to those who receive needed services. The provision of needed services to CSHCN is important in promoting their health and improving their functionality, quality of life, and integration into society (Stein \& Silver, 2005). Many researchers have evaluated the impact of services on family's satisfaction and unmet health care needs, but only few examine functional outcomes associated with primary care service models (Cooley, 2004).

Care coordination and family-centered care are two essential elements in the health care outcomes of CSHCN. Care coordination helps facilitate the linkage of CSHCN and their families with needed health and related services and depends mostly on the effective communication between medical providers and the family (McAllister, Presler, \& Cooley, 2007). According to the 2005-2006 National CSHCN Survey, 31.8\% of CSHCN families reported lack of one or more aspects of care coordination (CAHMI, 2005-2006). Families usually struggle to find the services that their children need and for which they qualify. Care coordination plays a critical role in helping parents to identify and access needed services and community resources with the goal to reach children's maximum health and potential (APP, 2005).

The characteristics of adequate care coordination include the development of a comprehensive plan of care through collaboration between the health provider and the family; the establishment of a confidential central record with the health and services information from the patient; sharing of information between the child, family, and providers, including reasons for referrals; linkage of families to parent support groups; evaluation and discussion of information from specialists with families; implementation 
of recommendations; and coordination with educational, public health services, financial assistance programs, and other community resources (Antonelli, Stille, \& Antonelli, 2008). It is recommended that primary physicians designate a specific care coordinator in the office, which can be a nurse, social worker, therapist, or other professional, to help in developing a plan of services according to the needs of patients and families and providing follow up with other health care professionals, payers, and community resources (AAP, 2005).

Primary care providers have a central role in care coordination for CSHCN. According to Cooley and McAllister (2004), primary care practices for children usually focus on preventive and acute care, and lack integration and coordination with other community resource services that include specialty, therapy, and education services, among others. The primary pediatric setting usually provides well-child and acute care, developmental screening, and preventive care. Care coordination offered in primary provider settings, such as in practices that are considered medical homes, is an alternative that can assist families in accessing diverse services in an efficient, effective, and organized manner (AAP, 1999). Several barriers have been identified in the provision of care coordination services, including the absence of a single point of evaluation and entry into the health care system and economic, social and cultural factors (AAP, 2005). According to the Institute of Medicine (2001), the lack of health services coordination in the population constitutes an important reason for the difference between the current health system and the system that society should have in order to provide effective and efficient services. 
Family-centered care is necessary in the care for CSHCN. Family-centered care is based on the notion that parents are experts in their children's health and needs; that families are different; and that children's functioning is optimized when families work in collaboration with providers in the health care process (King, Teplicky, King, \& Rosenbaum, 2004). Families should be active participants in health care decision making and be informed of children's health conditions by providers. According to the national CSHCN survey, an estimated $34.5 \%$ of $\mathrm{CSHCN}$ did not receive care that is considered to be family-centered (CAHMI, 2005-2006). A policy statement of the American Academy of Pediatrics on family-centered care recognizes the value of information that families bring into the care process and their important role in decision making to achieve better children's health outcomes, improved resources allocation and increased satisfaction (AAP, 2003). Family-centered care providers consider families as the primary caregivers of children and their main sustain and support.

Family-centered pediatric practices consider families as key partners in the care of children; show respect for their culture, customs, traditions, and expertise; and provide flexibility according to families' needs and preferences. This partnership helps promote good communication between providers and families, share of information and effective decision making while at the same time improve children's health and general functioning. Family-centered care can enhance families' and professionals' satisfaction with care, build confidence, promote effective service use, and contribute in decreasing health care costs (AAP, 2003). The Institute of Medicine (2001) recommended that patients and families participate and be well informed in the health care process. Family- 
centered care should not only be integrated into pediatric practices, but also in hospitals, community settings, and clinics where $\mathrm{CSHCN}$ receive services.

\section{Problem Statement}

A gap exists in the literature regarding the impact of care coordination and family-centered care on children's functionality. Previous studies have focused on met and unmet health care needs and associated factors in the process of care for CSHCN, but not on health outcomes or functionality. This limitation has been previously identified in the literature, indicating a need to develop studies to address this issue (Cooley, 2004). This study was developed based on this need and with the purpose to obtain information to determine if care coordination and family-centered care are associated with CSHCN's functional abilities, after adjusting for other variables.

Functional ability in this study refers to the capacity or ability of a child to do activities that most children of the same age can do, including physical and/or mental activities. A child can be limited or prevented in his/her functional ability if he/she cannot perform as much or at all the activities that most children of the same age can perform, like for example, moving, breathing, learning, self-caring, and communicating. The information gathered from this study may contribute to expanding knowledge in this area and help in the development of public policies and programs geared to improve the health care outcomes of CSHCN and their families.

\section{Nature of the Study}

This study is a secondary data analysis of the 2005-2006 National Survey of Children with Special Health Care Needs (NS-CSHCN). The NS-CSHCN collected information through household telephone interviews with parents of CSHCN less than 18 
years of age at the state and national levels. The purpose of the survey was to determine the prevalence of children with special needs and obtain information about children's demographics, health conditions, functionality, access to care, use of services, care coodination, family-centered care, adequacy of health insurance, medical home, family satisfaction with care, transition of youth to adult life, and impact of special needs on the family. The national survey was sponsored by the Maternal and Child Health Bureau and implemented by Centers for Disease Control and Prevention's National Center for Health Statistics (CDC, 2009).

I analyzed data from a sample selected from the 2005-2006 NS-CSHCN database with the purpose to determine if care coordination and family-centered care are associated with functional ability in CSHCN. Analyses were adjusted for other variables and stratified by health conditions to evaluate potential confounding. Details about sample size and analyses methods used in this study are provided in Chapter 3.

\section{Research Questions and Hypotheses}

Research questions and hypotheses for this study were:

Research question 1: Is care coordination associated with the ability of CSHCN to perform activities that most children of the same age can perform generally, including physical and/or mental activities, adjusting for other variables?

$\mathrm{H}_{0}$ : Care coordination is not associated with the ability of CSHCN to perform activities that most children of the same age can perform generally.

$\mathrm{H}_{\mathrm{A}}$ : Care coordination is associated with the ability of CSHCN to perform activities that most children of the same age can perform generally. 
Research question 2: Is family-centered care associated with the ability of CSHCN to perform activities that most children of the same age can perform generally, including physical and/or mental activities, adjusting for other variables?

$\mathrm{H} 2_{0}$ : Family-centered care is not associated with the ability of CSHCN to perform activities that most children of the same age can perform generally.

$\mathrm{H} 2_{\mathrm{A}}$ : Family-centered care is associated with the ability of CSHCN to perform activities that most children of the same age can perform generally.

These hypotheses were evaluated controlling for other variables. Additional details about the study methodology is discussed in Chapter 3.

\section{Purpose of the Study}

The purpose of this secondary-data analysis study is to determine if there is an association between care coordination, family-centered care, and functional ability of children with special health care needs. Functional ability refers to the capacity or ability of CSHCN to do things that most children of the same age can do in general.

\section{Theoretical Framework}

\section{Medical, Functional, and Social Models of Disability}

The essential functions of public health encompass assessment, public policy development, and assurance (Turnock, 2004). Public health initially focused on reducing mortality and morbidity caused by infectious diseases and more recently by chronic diseases. Disability has been an area of less public health attention due in part to the ambiguity of its definition, the lack of a unifying framework that could clearly define disability, and associated factors and the diverse types of disabilities and severity experienced by affected people (Lollar \& Crews, 2003). Disability can result from birth 
defects, the occurrence of acute diseases, injuries, or the presence of comorbid chronic diseases. Lollar and Crews (2003) discussed various frameworks that have been used to define and address disability in public health. For example, the medical model views disability as a consequence of an individual specific disease or health impairment. The Activities of Daily Living (ADLs) is a medical model that views disability as a limitation of the individual in achieving basic life activities including the inability to walk, bath, dress, toilet, and feed (Katz \& Akpom, 1976), and the inability to perform other types of activities known as Instrumental Activities of Daily Living (IADLs), including housekeeping, shopping, cooking, telephone use, and financial administration (Lawton \& Brody, 1969).

Compared to the medical model, the functional model considers a disability as a consequence of impairment in medical, physiological, and /or cognitive health (Drum, 2009). The functional approach is used in diverse government programs to provide services to individuals to improve functionality. The model recognizes the impact of a health condition in the functionality of an individual, but mainly focuses on the functional impairment or disruption per se (Drum, 2009). Services can be offered to address functionality in order to improve the ability of affected individuals to engage in activities necessary for living. For example, the Social Security Act, Section 223(d) (2) considered a disability as an impairment that affects the capacity of an individual to work and be part of the economy (Drum, 2009). Another example is the Developmental Disabilities Assistance and Bill of Rights Act of 2000, which considered a disability as a mental and/or physical impairment that begins before age 22 and that can result in functional limitations in main life activities, that include, self-care, communication, learning, 
mobility, self-direction, independent living, self-determination, and work (Drum, 2009). This act indicated that individuals with functional limitations need a variety of services in a planned and coordinated way in order to promote their productivity, independence and integration into the community (Drum, 2009). This act is used as a basis in the provision of service programs to persons with disabilities.

The social model of disability differs from the medical and the functional model by viewing disability as a consequence of the interaction with the environment (Bickenbach, 2001). This model focuses on the environmental-external perspective rather than in the individual-internal perspective. Environmental factors have been associated with the health state of people with disabilities. The social model describes the interaction of environmental factors in the process of disability and the level of functioning of the person in society. For example, people in poverty may encounter access barriers to health care services, which may expose them to conditions or injury that may increase the risk for disability. The level of education is also important because people with a higher educational level tend to seek medical care, comply with treatment, and usually have a healthy lifestyle, which contributes to fewer disability limitations (Lollar \& Crews, 2003).

\section{Theoretical Models related to Children with Special Health Care Needs}

One of the models used to study the health services system for CSHCN is the Behavioral Model of Health Services Use (Andersen, 1995). This model has been adapted to study factors associated with access and easy of use of community-based services for CSHCN. Baruffi, Miyashiro, Prince, and Heu (2005) used an adapted version of this model to identify factors that represent difficulties for $449 \mathrm{CSHCN}$ families in 
using community-based services with the purpose to provide recommendations for service system improvement in Hawaii. The model was based on the assumption that health services and satisfaction depend on predisposing factors such as demographics, health beliefs, and social structure; enabling factors, such as personal and family factors, characteristics of the health system; service availability; and perceived need for services. Specific independent or explanatory variables in the study by Baruffi et al. (2005) were evaluated according to this model including child health conditions (functional limitation, severity of condition, and type of service need); predisposing factors that include child and family characteristics (age, maternal level of education, level of poverty); and enabling or health services factors (family-centered care, coordinated care, health insurance adequacy). The association between independent and dependent variables was evaluated using bivariate and multivariate analysis techniques. General functional limitation was measured through parental reports. Severity of condition was determined based on parental rating of health problems in a scale from $0-7$, in which $0-2$ corresponded to mild severity, 3-6 corresponded to intermediate severity, and 7-10 corresponded to a very severe condition.

Results of the study by Baruffi et al. (2005) using an adapted Behavioral Model of Health Services Use indicated that factors at the level of health services (enabling factors) were statistically associated with how easy families used community-based services. For example, the risk for experiencing difficulties in using community-based services was almost 5 times higher for families that were not considered as partners in decision making $(\mathrm{OR}=4.68,95 \% \mathrm{CI} 1.99-11.01)$; three times higher for families who did not receive family-centered and coordinated care $(\mathrm{OR}=2.95,95 \% \mathrm{CI} 1.33-6.58)$, and 2.7 times 
higher for families without adequate health insurance $(\mathrm{OR}=2.69,95 \% \mathrm{CI} 1.31-5.50)$, compared to families who participated in decision making, families who received familycentered and coordinated care, and families who have adequate health insurance, respectively.

Benedict (2006) also employed the Health Behavior Model in the study of how family resources predict use of supportive and therapeutic services by children with limitations in functionality comparing medical and educational settings. The authors found that having public health insurance (enabling factor) and a higher level of household education (predisposing factor) were positively and significantly associated with the use of supportive and therapeutic services in both medical and educational settings. This data may indicate disparities in health service use by CSHCN families according to health insurance status and level of household education. This information is important to be considered in the revision of policies and programs for CSHCN and their families.

Several CSHCN studies have used a different approach to evaluate factors associated with health outcomes and health care for CSHCN. Many of these studies use a multidimensional or socio-ecological model that explores the effects of the individual, family, and community determinants in the health of CSHCN (Fisher-Owens et al., 2007; Newacheck, Rising, \& Kim, 2006). These models are based on the socioecological model of disease that evaluates a complex interaction of factors that influence health from a population perspective (IOM, 2003). This model is based on the interaction of several components that affect health outcomes, including individual demographics, biology, family, community and social environment; working and living situations; the health 
care system; and the cultural, economic, political and environmental components. Other studies on CSHCN have used a modified version of the socioecological model developed by the National Committee on Vital and Health Statistics that is based on a broad view of the factors that influence population's health (NCVHS, 2002). The modified model employed in these studies uses a multilevel socioecological approach and categorizes the factors or determinants into child, family, community, and societal levels.

I used an adapted version of the socioecological model to study the relation of child, family, community and society factors with functional ability in CSHCN. This model was selected based on previous research literature that considers the importance of these factors on children's health outcomes. Child level determinants included the child's sociodemographics and health conditions. Family-level determinants included household poverty level and household educational level. Community and society level determinants included health insurance, care coordination and family-centered care. Figure 1 shows the relation between these level determinants and the functional ability of CSHCN. 
Child-level characteristics:

Age, gender, race, number of health conditions

Family-level characteristics:

Household poverty level,

household educational level

Community level characteristics:

Health insurance, type of health

insurance (public/private)

Society-level characteristics:

Care coordination and familycentered care

Figure 1. Diagram that depicts the multilevel variables in relation to children's functionality based on the socioecological model.

\section{Definition of Terms}

Children with Special Health Care Needs (CSHCN) are defined by McPherson et al. (1998, p.138) as "children who have or are at increased risk for a chronic physical, developmental, behavioral, or emotional condition and who also require health and related services of a type or amount beyond that required by children generally". Children with special needs usually have health chronic diseases or conditions that require them to use more services compared to children in general.

Functional ability refers to the capacity or ability of a child to do things or activities that most children of the same age can do (CDC, 2005-2006). The study focuses on abilities in general functional areas, which include mobility, breathing, studying, selfcaring, and communicating, among others. 
Care coordination (CC) is defined by the American Academy of Pediatrics as "a process that links children with special health care needs and their families to services and resources in a coordinated effort to maximize the potential of children and provide them with optimal health care" (APP, 1999, p. 978, para.1). Care coordination is necessary for the effective and efficient organization and provision of resources which helps increase CSHCN access to needed health care services.

Family centered care (FCC) is defined as the provision of health services to children that consider the active role and participation of families in health care decision making in collaboration with health care professionals (DHHS, 2004). This type of approach strengthens the relationship of $\mathrm{CSHCN}$ families and health care providers.

\section{Assumptions, Scope of Study, and Limitations}

This study used secondary data. The use of secondary data has many benefits. Data for this study were collected through a large national representative sample from a survey that was designed by experts in the field of maternal and child health. The use of large samples increases precision of estimates and permit to make generalizations to the population (Trochim \& Donnelly, 2007). Additionally, data were used from the second time that the national survey is implemented in the US. It was first implemented in 20002001 which provided the opportunity to revise and add new questions in order to improve the questionnaire for subsequent surveys (DRC, 2005). Despite its benefits, secondary data analysis also poses some limitations. The original survey may have been designed for a purpose different from the present study. This can affect the availability of variables that might be of interest to the investigator. In many cases, considerable time has passed since the data were collected, which may not reflect changes in the health care 
environment (NIH, n.d.). Other limitations relate to the observational nature of the study. Data collected in the national survey are considered self-reported data, which cannot be corroborated with other data sources, such as medical records or service claims, and is subjected to recall and reporting bias. Recall bias may occur that can affect the quality of data because respondents may have difficulties remembering remote service encounters compared to recent events.

\section{Significance of Study, including Positive Social Change}

This study contributed to society by focusing on two fundamental health care system's elements, care coordination and family-centered care in relation to CSHCN's functional ability. These two elements are necessary to assure that services meet the health needs of this population and foster their appropriate development, optimum health and quality of life. The current health care system for this population has been described as a fragmented one in which families have difficulties navigating the system to obtain the necessary health and related services for their children (Roberts, Behl, \& Akers, 2004). Evidence obtained from this study can be used by health care providers, governmental agencies, policy makers, and other stakeholders in improving the health care system and in developing interventions or programs for this population in the United States.

\section{Summary}

Chapter 1 provided a brief introduction to the present study, its problem statement, nature of study, purpose, research questions and hypotheses. Information is also provided on theoretical bases on disability, including the medical, functional, social, and socioecological models. This chapter also provided definitions of terms and included 
sections with information on assumptions, limitations, scope of study, significance of study, and positive social change.

CSHCN usually require diverse services and in greater quantity compared to children in general. These children can have chronic conditions and diseases with different consequences on health, including increased medication use, limited activity and functionality, and increased needs for special therapies and mental health services. The health care system should provide services to improve children's health outcomes, including functionality. Care coordination provided by the primary doctor can help families to locate and access services in the community. Family-centered care provides the opportunity to the family to actively participate in health care decision making.

Limited research evidence has evaluated the role or impact of care coordination and family-centered care on children's functionality. The present study can help provide information to determine if care coordination and family-centered care are associated with functional abilities in CSHCN using representative data from a national CSHCN survey. The information gathered from this study may contribute to the development of public health programs to improve the health of CSHCN.

Chapter 2 provides information on research studies, theoretical models specific for CSHCN, a discussion of the conceptual relationship of study variables, and research evidence on care coordination and family centered care. Chapter 3 describes the research methods, the study design and approach, setting and sample, data collection, questionnaire, study variables, statistical analysis methods, and measures to protect participants'rights. Chapter 4 presents the analysis results and Chapter 5 discusses the results, their implications, and recommendations for social change. 


\section{Chapter 2: Literature Review}

\section{Introduction}

This section provides a background of research on the elements that are considered important in the adequate care for CSHCN. The chapter begins with a description of the literature search methods and keywords used to retrieve peer-review research articles. The chapter continues with information on the study conceptual framework to study factors that affect the functional ability of CSHCN. Information is also provided on the health care service needs of CSHCN and the importance of having an adequate health insurance to access services. This information serves as a background for discussion about the importance of the medical home and its two most important health care components, care coordination and family-centered care, on health outcomes including functionality.

\section{Methods for Retrieving Articles for Literature Review}

Methods of searching the scientific literature included diverse search engines including Academic Search Complete provided by Walden University, PubMed of the National Library of Medicine, the Pediatrics journal of the American Academy of Pediatrics, the Maternal and Child Health Journal, and the American Journal of Public Health. The Academic Search Complete of Walden University's Library is a scholarly full text database of over 6,000 peer-review multidisciplinary journals. Key words used in searching articles included the following: children with special health care needs, children with disabilities, children with chronic conditions, care coordination, familycentered care, functional limitation, functional ability, CSHCN system of care, health insurance coverage. Some of these keywords were combined with the "CSHCN" term in 
order to limit the articles to those related to this population only. Articles were searched for the past 10 years. Older articles were generally excluded from the research, except in cases where the article contained original research or information of relevance to the present study. Articles that did not address children with special needs or the topics under study were excluded from the review. Several governmental and other websites were also searched for information on CSHCN, including the CDC's National Survey of CSHCN website, the Data Resource Center for Child and Adolescent Health of the Oregon Health and Science University, and the National Center for Medical Home Implementation of the American Academy of Pediatrics.

\section{Conceptual Framework}

Many studies on CSHCN health services and outcomes use the socioecological model as a theoretical framework. This model considers the complex interaction of factors that influence health from a population perspective (IOM, 2003). The model includes factors at the child, family, community, and broad social levels. For example Newacheck, Kim, Blumberg, and Rising (2008) used an adapted version of the socioecological model to evaluate risk factors for special health needs in children. Risk factors in the study were classified into different levels or determinants in relation to their effect on CSHCN's chronic conditions and special needs. Child-level determinants included child's genetic endowment, development, predisposing characteristics (gender, age, race/ethnicity), health and behavior (breastfeeding, number of nights child got enough sleep, number of hours child watch television, if parents exercise or participate in sports). Family-level determinants included parental education and health status, family income, parental health behaviors or practices, and social support. Community-level 
determinants included community physical (census region of household, household located in the metro area, someone in the household smokes) and social environment (highest education in household, primary language in home, number of biological parents or stepparent in home, closeness of parent to child, behavior during parental disagreements, supportive neighborhood, household income, federal poverty level, someone employed for more than 50 weeks last year), health care access, public safety and schools' performance. Society level determinants included characteristics of the health care system, racism and socioeconomic inequities (Newacheck et al., 2008). The study found that genetic endowment and the social environment were associated with an increased risk for special needs in CSHCN, while the physical environment was significantly associated with an increased risk for special needs in school-age CSHCN. This study used an adapted version of the sociecological model to study factors associated with functional ability in CSHCN.

\section{Health Care Service Needs of CSHCN}

Few research studies in CSHCN have addressed the topic of CSHCN's functional ability and its relationship with health care characteristics. Systems of care for CSHCN are characterized by the existence of a variety of organizations, agencies, and providers that offer services to this population. Many of these components differ in their eligibility criteria, type of services, funds, and types of professionals (AAP, 1999). CSHCN families have often expressed barriers and challenges in identifying and accessing needed services. According to Erickson-Warfield and Gulley (2006), children with chronic conditions need access to high quality medical care in order to promote their healthy development and well-being. In order to study this population, it is necessary to utilize a 
broad approach to conceptualize the term special health care needs that may vary from mild and manageable chronic conditions to complex and difficult to manage health conditions (Bethell, 2000). Therefore, children with special needs present variable needs in terms of type and severity of condition or health consequences (Perrin, 2002).

CSHCN are at increased risk for having service access problems. Van Dyck, Kogan, McPherson, Weissman, and Newacheck (2004) examined the needs and service use by CSHCN and their families using a national survey sample. They found that $17.7 \%$ of CSHCN had an unmet need for any of 14 primary and specialty care services, $7.5 \%$ did not have a usual source of care, $21.9 \%$ had difficulties with referrals, and $33.5 \%$ of families were not satisfied with services. Mayer, Skinner, and Slifkin (2004), who analyzed data from the first National Survey of CSHCN, found that $3.2 \%$ of children who needed routine care did not get it, while $7.2 \%$ of those who needed specialist care did not get it.

Various studies have explored the utilization of services by CSHCN and have found that it varies according to child and family characteristics and insurance coverage. Child characteristics include the number and type of health conditions and limitations in activity (Shenkman, Wu, Nackashi, Sherman, 2003; Weller, Minkowitz \& Anderson, 2003). Family characteristics associated with greater utilization include high educational level and high household income (Weller et al., 2003; Witt \& Riley, 2003).

\section{Health Insurance}

Families usually report problems accessing services when their children lack an adequate health insurance that cover for needed services. Health insurance has been found to be a predictor in health care utilization by $\mathrm{CSHCN}$, especially if children are 
covered with public health insurance (Newacheck, McManus, \& Fox, 2000). In general, these studies have found that low income and lack of health insurance are the most common reasons for not meeting the needs of CSHCN. According to the US Department of Health and Human Services (2008), an estimated 38\% of children with special needs lack an adequate public or private health insurance to cover services they need. Additionally, in a study using data from the National Health Interview Survey, it was found that approximately $14 \%$ of $\mathrm{CSHCN}$ with health insurance had at least one unmet service need (Davidoff, 2004).

Kogan, Newacheck, Honberg, and Strickland (2005) studied the effect of underinsurance on service access and utilization and children's ability on their daily functions using data from the 2001-2002 NS-CSHCN. Underinsured children were those with inadequate health insurance. In the study an estimated $95 \%$ of CSHCN had health insurance and $32 \%$ of these were underinsured. Hispanics, people in poverty, and children who were most limited in their daily activities were the most likely to be underinsured.

Tippy, Meyer, Aronson, and Wall (2005) found that health insurance adequacy is important in assuring access to needed services. CSHCN with adequate health insurance were two times more likely $(\mathrm{OR}=2.3,95 \% \mathrm{CI} 1.5-3.5)$ to have comprehensive coordinated care compared to children with inadequate health insurance. Baruffi et al. (2005) also found that CSHCN without adequate health insurance or underinsured have almost three times the risk for reporting difficulties in the use of community-based services $(\mathrm{OR}=2.69,95 \% \mathrm{CI} 1.31-5.50)$ compared to $\mathrm{CSHCN}$ with adequate health insurance. Underinsured children with severe conditions had an increased risk for having 
difficulties with community-based services use $(\mathrm{OR}=2.82,95 \% \mathrm{CI} 1.14-6.96)$ compared to children with less severe conditions. The information gathered by these studies is important in assessing existing public policies and in identifying strategies to improve CSHCN programs and services.

Stein and Johnson-Silver (2005) analyzed data from the 2001-2002 NS-CSHCN and the Kaiser Family Foundation to evaluate if rates of functional limitations among CSHCN were associated with having health insurance coverage, unmet health needs, and amount of Medicaid spending per child. Functional limitation was measured through the combination of two questionnaire items that addressed how often health conditions affected the child's ability to do things compared to other children of the same age (always, usually, sometimes, never) and how much was affected (a great deal, some, very little). Children were determined to have a functional limitation if parents indicated that their children were always or usually affected in their abilities and in great deal. Results from correlation analyses showed that the proportion of CSHCN with functional limitations was higher in states with higher rates of CSHCN without health insurance $(r=$ $0.49, p<0.0001)$ and in states with higher rates of CSHCN with unmet health care needs $(r=0.62, p<0.0001)$. When correlation measures were squared for both variables, it was found that lack of insurance and unmet needs explained $24 \%$ and $38 \%$ of the variance of state percentages of CSHCN with functional limitations, respectively. In contrast, Medicaid spending per child was not found to be related to the proportion of CSHCN with functional limitations ( $r=0.05$, not significant). The authors of the study also evaluated the factors using multiple regression analyses controlling for federal 
poverty level and found that variables that were significant in correlation analyses were also statistically significant variables in multivariate analyses $(p<0.001)$.

\section{CSHCN's Health Care Components}

\section{The Medical Home}

The health care system for CSHCN should comply with certain components in order to assure that this population receives the services they need in order to improve their health, general functioning and quality of life. Several public policies have been published by the American Academy of Pediatrics (AAP) to improve health care services for CSHCN. These policies address the importance of the medical home concept and its components. A medical home is a model of primary and pediatric health care services provision in which children receive comprehensive, appropriate and trustworthy services in an organized manner and in which families are considered an active participant in health care decision making. The AAP released a policy that described the medical home concept, which clarified that a medical home does not refer to a house, building, or health care facility, but referred to the concept of how health care should be provided to CSHCN to promote children's healthy development toward adulthood (AAP, 2002). To consider a primary practice setting as a medical home for children with special needs, services need to be accessible, comprehensive, continuous, coordinated, family-centered, compassionate, and sensitive to families' cultures and values. The AAP policy provided an in-depth description of each component, including care coordination and familycentered care, two essential elements in assuring services for CSHCN.

The medical home can promote better health outcomes for CSHCN. A study that reviewed research studies and interventions on the effect of medical home on various 
health care and health outcomes of CSHCN found that the medical home translated into improvements on mental health, better general health status, and decreased school absences (Homer, Klatka, Romm, Kuhlthau, Bloom, Newacheck, Van Cleave, \& Perrin, 2008). For example, in an evaluation of a medical home intervention it was found that children with chronic conditions had a better mental health status after 6 months, 1 year and 4-5 years of follow-up compared to children with chronic conditions who received standard care in an ambulatory setting (Stein \& Jessop, 1991). The level of psychological adjustment of participants was measured using the Personal Adjustment and Role Skills (PARSII) scale and compared results using pre and post tests. Participants in the medical home care intervention had significantly better psychological adjustment at 6 months $(p=$ $0.041), 1$ year $(p=0.076)$ and 4-5 years $(p=0.026)$ of follow-up compared to children who received standard health care. These results may indicate the benefit of the medical home in achieving better health outcomes in children with special needs.

\section{Care Coordination}

Most research on $\mathrm{CSHCN}$ focus on identifying the factors that affect the provision of care coordination services and only few have evaluated the impact of care coordination on health outcomes. One of these studies evaluated the effect of care coordination activities provided by pediatric practice settings to $\mathrm{CSHCN}$ and found that care coordination translated into cost savings through the prevention of unnecessary health outcomes, such as, reduced visits to the pediatric office or clinic and lowered emergency room visits, subspecialist visits, hospitalizations and specialized therapies (Antonelli et al., 2008). Most care coordination encounters focused on diverse areas including coordination of services among the different providers (44\%), clarification of families' 
expectations on the health care plan $(21 \%)$, arrangement of appointments and referrals (16\%), and attention of multiple needs of CSHCN and their families (25\%). Care coordination use was higher for families with social stressors or complications.

Palfrey, Sofis, Davidson, Liu, Freeman, and Ganz (2004) studied the impact of a pilot project of care coordination and integrated services on children's hospitalizations, family's satisfaction and parental work-days lost. The project was named "Pediatric Alliance for Coordinated Care (PACC)" and was implemented in six pediatric offices in the area of Boston, Massachusetts with the participation of approximately $150 \mathrm{CSHCN}$ and their families. The project was characterized by a high level of commitment and leadership from both primary care providers and families. Care coordination and followup services were mainly provided by a pediatric nurse practitioner. Results of the intervention showed a statistically significant decrease in children's hospitalizations ( $58 \%$ baseline vs. $43.2 \%$ after intervention; $p<0.01)$, and a decrease in the rate of parental missing work days in excess of 20 days (26\% baseline vs. $14.1 \%$ after the intervention; $p=0.02$ ). Families of children with severe conditions were most likely to easy use care services and to be more satisfied with services when they obtained the help of the pediatric nurse practitioner. Authors recommended the replication of the project in large scale in order to obtain additional evidence of the benefit of a coordinated, integrated and family-centered care on CSHCN health outcomes.

Information from health care providers, especially pediatricians, is valuable in assessing care coordination services and barriers they face in providing health care. A survey of pediatricians, members of the American Academy of Pediatrics, was implemented in year 2000 to collect information on care coordination services provided 
to CSHCN (Bhushan-Gupta, O'Connor and Quezada-Gomez, 2004). According to participants, approximately $26.9 \%$ of the population in primary practice settings was composed of CSHCN. Significantly more pediatricians reported to provide a higher frequency of services to $\mathrm{CSHCN}$ compared to non-CSHCN, including contacting the school to discuss child's health and educational needs ( $23.7 \%$ vs. $17.8 \%, p<0.001)$, integrating the medical care plan with other providers' care plans $(49.1 \%$ vs. $41.0 \%, p<$ $0.001)$, assisting the family in obtaining an appointment with a specialist $(61.4 \% \mathrm{vs}$. $59.1 \% ; p<0.001$ ), spending enough time with the child's family to discuss the results of visits to a specialist $(18.8 \%$ vs. $15.0 \%$; $p<0.001)$, meeting with the discharge planning team when child was hospitalized $(23.7 \%$ vs. $19.3 \% ; p<0.001)$, and discussing other family's needs ( $40.5 \%$ vs. $31.2 \%$; $p<0.001)$. The survey also collected information on barriers that pediatricians face in providing care coordination services to CSHCN. Reported barriers included lack of time, insufficient medical and office staff, lack of community and government services in the area, difficulties in communicating effectively when developing an integrated medical care plan, inadequate payment or reimbursement for services, and lack of training on care coordination and on identifying families' potential needs for other services (Bhushan-Gupta et al., 2004).

In summary, several studies have found that care coordination services help improve health outcomes of CSHCN, including reduced visits to the pediatric office or clinic, lowered emergency room visits and subspecialist visits, less hospitalizations, and reduced use of specialized therapies (Antonelli et al., 2008). Care coordination also promotes family's satisfaction with services (Palfrey et al., 2004). Despite the recognized benefits of care coordination, pediatricians have reported several barriers in 
providing these services, including inadequate payment or reimbursement for services, lack of time and personnel, lack of community-based services, problems in communicating effectively with other providers during the development of a care plan, and lack of education on care coordination aspects (Bhushan-Gupta et al., 2004). These barriers need to be addressed by policy makers in order to promote care coordination and its benefits for CSHCN.

\section{Family-Centered Care}

Research studies have found evidence on the importance and benefits of familycentered care on meeting the health care needs of CSHCN. For example, EricksonWarfield and Gulley (2006) implemented a study with 2,100 CSHCN families from 20 states representative of the four main US Census regions (northeast, midwest, south, west) with the purpose to expand knowledge on parental perceptions of health care services, met and unmet needs and service access problems. The authors found that children with higher health needs are usually the ones with poorer health, severe conditions and less stable health. Unmet health needs reported by parents ranged from three percent for specialized services to $12 \%$ for mental health services. Unmet needs significantly increased with the increase in number of needs for services, especially among children with changing needs compared to children with stable needs $(\mathrm{OR}=3.39)$ and those with severe limiting conditions compared to children with mild conditions (OR $=2.34)$. These children would benefit from pediatric practices with the characteristics of family-centered care included in the health care process.

Family-centered care is an essential element in the care for CSHCN. Families are more satisfied with services when providers consider them as active partners in the health 
care decision process for their children. According to data from a national survey, it has been estimated that approximately eight percent $(8 \%)$ of $\mathrm{CSHCN}$ families reported to be dissatisfied with health care services (Ngui \& Flores, 2006). A significant higher risk for service dissatisfaction was observed in families with children with severe conditions (OR $=1.14,95 \% \mathrm{CI} 1.06-1.22, p<0.05)$ compared to families with children with less severe conditions; families with uninsured children $(\mathrm{OR}=1.71,95 \% \mathrm{CI} 1.04-2.82)$ compared to families with insured children; and families who were interviewed in Spanish language $(\mathrm{OR}=2.25,95 \% \mathrm{CI} 1.06-4.76)$ compared to families interviewed in other language (Ngui \& Flores, 2006). Minority parents reported to be significantly more likely than White parents to not meet family-centered care elements, for example, to report that their providers sometimes or never spent enough time with their child, did not listen to the family carefully, were not sensitive to family customs and values, did not provide enough information to the family, and did not help the family feel like partners in the child's care $(p<0.001)$. Another study also found that families that did not receive family-centered care were at significant higher risk for service dissatisfaction $\left(\mathrm{OR}_{\mathrm{aj}}=9.15,95 \% \mathrm{CI} 7.24-\right.$ 11.6) compared to families that were considered partners in care, adjusting for race, age, poverty status, gender, and health insurance (Denboba et al., 2006).

Family-centered care is also associated with outcomes in CSHCN, including missed school days due to health conditions, unmet health needs and unmet family needs. A study of national data found that families that never or sometimes felt like partners in care were at a significant increased risk for having children who missed school days due to their health conditions $\left(\mathrm{OR}_{\mathrm{aj}}=1.22,95 \% \mathrm{CI} 1.01-1.46\right)$ compared to families that always or usually were considered partners in care, adjusting for race, ethnicity, age, 
poverty status, gender, and health insurance (Denboba et al., 2006). Families that never or sometimes felt like partners in the health care process were also at a significant increased risk for having children with unmet health needs $\left(\mathrm{OR}_{\mathrm{aj}}=2.54,95 \% \mathrm{CI} 2.19\right.$ $2.95)$ and unmet family needs $\left(\mathrm{OR}_{\mathrm{aj}}=2.69,95 \% \mathrm{CI} 2.16-3.36\right)$ compared to families that usually or always felt like partners in health care adjusting for race, ethnicity, age, poverty status, gender, and health insurance (Denboba et al., 2006).

Despite the research evidence on the benefits of family-centered care, the literature is scarce regarding health outcomes associated with it. A review study of available research on the effect of family-centered care on health outcomes in children with cerebral palsy found that literature mainly focused on two outcomes: development of skills and psychological health (King et al., 2004). One of the reviewed studies found that children with cerebral palsy improved their skills and development after participating in a family-centered health care program compared to children that participated in a standard program (Law, Darrah, Pollock, King, Rosenbaum, Russell, Palisano, Harris, Armstron \& Watt 1998). Other studies found that family-centered care promoted healthy psychosocial development in children with chronic conditions that participated in a service program that focused on the family compared to children that received services from a general health care program (King et al., 2004). Other studies focused on parental outcomes and found that family-centered care translated into better psychological health in mothers of children with chronic conditions mainly due to their active participation in the health care process and increased sense of competency, control and well-being (King et al., 2004). 


\section{Summary of Methodological Issues}

There is scarce literature on the effect of care coordination and family-centered care on CSHCN functional ability. Most studies on care coordination and familycentered care focus on met and unmet needs and family satisfaction with services. Majority of studies on this area are secondary data analyses and most use data from large national surveys, especially the 2001-2002 and 2005-2006 National Survey of CSHCN. Only one study evaluated the effect of care coordination on CSHCN's health through a pilot program intervention (Palfrey et al., 2004) and one evaluated the effect of familycentered care on health in patients with cerebral palsy (King et al., 2004). More research is necessary to gain knowledge on health outcomes associated with care coordination and family-centered care in CSHCN.

\section{Summary}

In conclusion, there is research evidence on the importance of care coordination and family-centered care in addressing the health care needs of CSHCN and their families but only few studies focus on the impact of these two health care elements on the health and functionality of CSHCN. CSHCN are at higher risk for having service access problems and families usually struggle in finding the services they need. CSHCN families have expressed that the health care system is fragmented and most families need that their primary care physicians provide them with care coordination and familycentered services in order to find and access the health care services that their children need (Erickson-Warfield and Gulley, 2006). Research articles on the benefits of these two components have revealed improved children's health outcomes. For example, a study by Homer et al. (2008) found that the medical home in general translates into 
reduced school absences and improved general children's health. Another study found that care coordination helped reduce children's hospitalizations, doctor office visits and use of therapies (Antonelli et al., 2008; Palfrey et al., 2004).

Care coordination requires that primary providers identify the needs of CSHCN and their families, know community resources and effectively communicate with other professionals in order to link families with needed services (Antonelli et al., 2008). Care coordination has been found to help in addressing health care needs and achieving better health outcomes. Despite its benefits, several barriers have been identified that can affect the role of the pediatric primary physician in providing care coordination, including lack of knowledge about special conditions and how to implement care coordination services in the office, lack of resources, communication difficulties with other health care providers, agencies and organizations, and the need for additional time in caring for children and providing information to families (Bhushan-Gupta et al., 2004). Another limitation is the inexistence or inappropriate reimbursement mechanisms for care coordination services (AAP, 1999).

Family-centered care is also a necessary component in the appropriate care for CSHCN. It has been found that families' satisfaction with services increase when providers consider families as partners in health care decision making process and are carefully listened about their needs and recommendations. Previous research studies have found differences in the receipt of family-centered care by race and severity of children's condition (Erickson-Warfield and Gulley, 2006). Family-centered care is also associated with family's satisfaction with health services. Ngui and Flores (2006) found that families of children with severe conditions were at a significant higher risk for 
lacking family-centered care compared to families of children with mild conditions. Families of uninsured children were also at increased risk for not receiving familycentered care compared to families with health insurance. Family-centered care can also have an impact on CSHCN's outcomes. It has been reported that children whose families never or sometimes were considered part of the health care process were at higher risk for missing school days due to their health conditions and for having unmet health needs compared to families who usually or always received family-centered care (Denboba et al., 2006).

This study was developed to determine if care coordination and family-centered care are associated with CSHCN's functionality, adjusting for other variables. The study was guided by the socioecological model. Chapter 3 provides a description of the methods that were used in this study to evaluate the research questions and hypotheses. 
Chapter 3: Research Methods

Introduction

The purpose of this study was to determine if there is an association between care coordination, family-centered care and functional ability in children with special health care needs using a nationally representative sample and controlling for other variables. To achieve the study purpose, the following research questions were investigated:

Research question 1: Is care coordination associated with the ability of CSHCN to perform activities that most children of the same age can perform generally, including physical and/or mental activities, adjusting for other variables?

Research question 2: Is family-centered care associated with the ability of CSHCN to perform activities that most children of the same age can perform generally, including physical and/or mental activities, adjusting for other variables?

This chapter describes the methods that were used to conduct the study, including a description of the research design, the dataset used in the study, the data collection tool and sampling procedures, measurement and operationalization of study variables and statistical analysis methods. This section also provides a description of measures taken for the protection of human participants' rights in the study.

\section{Research Design and Approach}

I analyzed data from the 2005-2006 National Survey of Children with Special Health Care Needs (NS-CSHCN). This survey collected data from random household residential telephone interviews with parents or guardians of CSHCN. The NS-CSHCN 
was sponsored by the Maternal and Child Health Bureau of the US Health Resources and Services Administration and implemented by the CDC National Center for Health Statistics (CDC, 2008). The objectives of the NS-CSHCN were to determine CSHCN prevalence at the state and national levels and to gather information about children's demographics and parental perceptions on children's health conditions, functional status, access to care, met and unmet service needs, care coordination, family-centered care, medical home, adequacy of health insurance, youth transition to adult life, and impact on the family. The present study analyzed data from a sample taken from the national survey.

\section{Setting and Sample}

The CDC developed a report that describes in detail the design, sample and operation of the 2005-2006 National Survey of CSHCN (CDC, 2008). This section provides a summary of the most relevant points of importance for the present study. The NS-CSHCN was conducted using the State and Local Area Integrated Telephone Survey (SLAITS) methodology using the sampling frame of the CDC's National Immunization Study (NIS) in order to efficiently identify households with age-eligible children. The NIS was implemented with the purpose to estimate vaccination coverage of children within geographic estimation areas. The NIS used a random-digit dial sample and computerized telephone (CATI) interviews to contact and select qualifying households. According to the CDC (2008), the NIS sample was selected based on 78 non-overlapping estimation areas that covered the United States. Each estimation area covered the area within each state border. The NS-CSHCN used the same sampling frame to identify 
households with children and to implement a screening to identify children with special health needs and complete 750 detailed interviews in each state.

\section{Population and Sample Selection}

The 2005-2006 NS-CSHCN main sample design was developed with the goal to obtain individual state samples and precise state and national CSHCN estimates. Precision was established on a maximum 10\% standard error for point estimates over 15\% (CDC, 2008). This was achieved by sampling at least 750 children in each state based on projected households with CSHCN in states' estimation areas. This projected number of households with CSHCN in each estimation areas was adjusted based on initial survey data collection and the expected proportion of households with children in each state. The number of household telephone numbers needed to be contacted was calculated based on the expected working residential number rate. This number was inflated to compensate for refusals and nonresponse. For the referent sample, there were not a specific number of interviews to complete per state. The sample of 6,000 was distributed among states based on the proportion of projected number of households with children less than 18 years of age in each state. A total of 192,083 households including 364,841 children were screened for special health care needs for the 2005-2006 National Survey of CSHCN from April 2005 through February 2007. Of these children, 56,014 had special health care needs and lived in 44,923 screened households (CDC, 2008). A total of 40,723 interviews with parents/guardians with children with special needs were completed for the main sample of children with special needs less than 18 years of age $(\mathrm{CDC}, 2008)$ The interview completion rate was $97.6 \%$, while the national response rate was 61\% (Denboba et al., 2006). 


\section{Sample Size}

A sample was randomly selected from the 40,723 records in the database. A sample size analysis was conducted to determine the minimum number of subjects that were needed in this study in order to detect a difference at a 95\% confidence level and $80 \%$ power. The sample size calculation was based on the estimates of CSHCN with the outcome and children's exposition to care coordination and family-centered care. Data were obtained from the Data Resource Center for Child and Adolescent Health website (CAHMI, 2005-2006). The OpenEpi sample size calculator for cross-sectional, cohort and randomized studies was used to determine the minimum required sample size for each hypothesis test (Dean, Sullivan, \& Soe, 2009). Table 1 and 2 show the results of the sample size calculations:

Table 1

Minimum Sample Size to Test Hypothesis 1(CC=Care Coordination)

\begin{tabular}{lllllll}
\hline $\begin{array}{l}\text { Power } \\
\text { percent }\end{array}$ & $\begin{array}{l}\mathrm{n} 1 \\
\text { did not } \\
\text { receive CC } \\
\text { (unexposed) }\end{array}$ & $\begin{array}{l}\text { n2 } \\
\text { received CC } \\
\text { (exposed) }\end{array}$ & $\begin{array}{l}\text { P1 } \\
\text { (Percent of } \\
\text { unexposed } \\
\text { with } \\
\text { outcome) }\end{array}$ & $\begin{array}{l}\text { P2 } \\
\text { (Percent of } \\
\text { exposed } \\
\text { with } \\
\text { outcome) }\end{array}$ & Alpha & $\begin{array}{l}\text { Minimum } \\
\text { Kelsey } \\
\text { Sample Size }\end{array}$ \\
\hline $80 \%$ & 12,576 & 18,395 & $48.8 \%$ & $59.0 \%$ & 0.05 & 776 \\
\hline
\end{tabular}

Note. Sample Size calculated using Openepi version 2.3 (Dean, Sullivan, \& Soe, 2009)

Table 2

Minimum Sample Size to Test Hypothesis 2(FCC=Family-Centered Care)

\begin{tabular}{|c|c|c|c|c|c|c|}
\hline $\begin{array}{l}\text { Power } \\
\text { percent }\end{array}$ & $\begin{array}{l}\text { n1 } \\
\text { did not } \\
\text { receive FCC } \\
\text { (unexposed) }\end{array}$ & $\begin{array}{l}\mathrm{n} 2 \\
\text { received } \\
\text { FCC } \\
\text { (exposed) }\end{array}$ & $\begin{array}{l}\text { P1 } \\
\text { (Percent of } \\
\text { unexposed } \\
\text { with } \\
\text { outcome) }\end{array}$ & $\begin{array}{l}\text { P2 } \\
\text { (Percent of } \\
\text { exposed } \\
\text { with } \\
\text { outcome) }\end{array}$ & Alpha & $\begin{array}{l}\text { Minimum } \\
\text { Kelsey } \\
\text { Sample Size }\end{array}$ \\
\hline $80 \%$ & 12,614 & 26,288 & $57.5 \%$ & $42.5 \%$ & 0.05 & 407 \\
\hline
\end{tabular}

Note. Sample Size calculated using Openepi version 2.3 (Dean, Sullivan, \& Soe, 2009) 
The minimum required sample is 776 to test for hypothesis one and 407 to test for hypothesis two. A sample size of 6,850 cases of the 40,723 cases was selected for this study. This sample size allows for stratified analysis by health condition group. The sample was randomly selected for this study using SPSS Random Cases Selection option. Table 3 shows the number of cases by health condition.

Table 3

Number of cases by health condition

\begin{tabular}{ll}
\hline Health condition & $\begin{array}{l}\text { Number of cases and } \\
\text { percent }\end{array}$ \\
\hline Allergies of any type & $20,936(53.0 \%)$ \\
Asthma & $14,916(38.8 \%)$ \\
Attention Deficit Disorder or Attention Deficit Hyperactive & $11,805(29.8 \%)$ \\
Disorder (ADD or ADHD) & $8,696(21.1 \%)$ \\
Depression, Anxiety or other Emotional Disorder & $5,907(15.1 \%)$ \\
Migraine or Frequent Headache & $4,252(11.4 \%)$ \\
Mental Retardation or Developmental Delay & \\
\hline
\end{tabular}

\section{Instrumentation and Materials}

\section{Data Collection Methods}

The sample in the national survey was selected by Random Digit Dialing (RDD) from groups of 100 consecutive telephone numbers (e.g. 773-257-0000 to 773-257-0099) that contained at least one residential telephone number listed in an updated directory (Tucker, Casady and Lepkowski, 1993). The sampling frame excluded cellular telephone numbers. The Maternal and Child Health Bureau collaborated with NCHS to establish the survey sample size and selection and questionnaire development. The NCHS 
contracted the National Opinion Research Center (NORC), University of Chicago, to administer the survey, computerize the data collection instrument, recruit and train the interviewers, conduct the telephone interviews, develop the databases and document the survey (CDC, 2008).

\section{Questionnaire Description}

The 2005-2006 NS-CSHCN's questionnaire has three parts. During the first part of the survey, an interviewer located a household telephone number and asked if there were children in the house and if the parent or caretaker was willing to participate in the survey. Then sociodemographic data were collected on all children in the house. In the second part of the survey, the interviewer asked five questions to the participant parent with the purpose to screen children for special needs in the house. The five screening questions were made for each child in the house and addressed the following: (a) use of medications, (b) use of services, (c) use of therapies, (d) activity limitation, and (e) emotional condition. Each question had two follow up questions: (a) the use was due to a condition and (b) with duration of 12 months or longer. These five screening questions were developed by the Maternal and Child Health Bureau based on the definition of CSHCN that addresses health consequences instead of diagnosis to identify children with special needs. The child had a special need if the parents answered yes to any of the screening questions and the two follow-up questions. Parents may have answered yes to more than one screening question. If there were more than one $\mathrm{CSHCN}$ in the house according to the screening, then one was randomly selected for the in-depth interview. The interview was based on this selected child. In other words, CSHCN in the sample $(40,723)$, may have qualified for the interview (for the survey, not program) if the parent 
answered yes to at least one of the screening questions and the two follow-up questions, and not necessarily to the functional limitation question. All screening questions are asked to the parent, so children in the survey sample may have a functional limitation or not because many have qualified through any, or one or more of the five screener questions. The third part of the questionnaire corresponded to the in-depth parental interview to collect data on health conditions, functionality, health care access, care coordination, family-centered care, adult transition, health insurance, impact on the family, family composition and income. The questionnaire was translated into several languages, with five percent of the interviews completed in a language other than English (CDC, 2005-2006).

\section{Data Quality}

The 2005-2006 NS-CSHCN questionnaire was computer programmed using the Computer Assisted Telephone Interview (CATI) system. This system allowed to document time and call recording and to control data-entry errors during the telephone interview. Warning message screens indicated the interviewer if the datum was not accepted by the system because it was out of range, missing or invalid and a different answer was necessary to be entered in order to continue with the interview. Although this system helped diminished errors during the interview, data cleaning was necessary to verify valid number of cases, to check permissible values in each variable, to delete invalid values, and to examine missing values. Interviewers received training that covered different topics, including (a) study goals, purpose and history; (b) study design; (c) techniques to gain participation and to manage refusals; (d) CATI questionnaire; (e) 
and practice with mock interviews. Interviewers were evaluated based on the performance on mock interviews and a written exam (CDC, 2008).

\section{Dataset Description}

The NS-CSHCN datasets are in the public domain and can be accessed at the CDC site http://www.cdc.gov/nchs/slaits/cshcn.htm. There are three datasets: one for the household records, one for the CSHCN screener and one for the in-depth interviews. These datasets are in SAS format. The Data Resource Center (DRC) of the Oregon Health and Science University provides a combined dataset of the 2005-2006 NSCSHCN in SPSS format that include the original survey data and additional indicators developed by DRC. This dataset is available to the public, but must be formally requested by filling a data use agreement form. This form requests information about the investigator, purpose of research and intended use. The DRC requires the investigator to reference the Center in the final study paper. Once the data use agreement form is approved, the database is released to the user.

\section{Description of the Study Variables}

The dependent variable was functional ability limitation. Functional ability refers to the capacity or ability of children to do things that children of the same age can do in generally. This variable is identified in the DRC database as "CSHCN3" with YES/NO response categories. This variable corresponds to the question that asks parents: "Is your child'/ 'Are any of your children') limited or prevented in any way in (his/ her/their) ability to do the things most children of the same age can do?" (2005-2006 NS-CSHCN Section 2, Initial Screening, p.13). Previous research studies have used this variable in their analyses (Baruffi et al., 2005; Porterfield \& McBride, 2007). 
Two independent variables were examined in this study: care coordination (CC) and family-centered care (FCC). Data collected on these two variables were based on questions that referred to services that $\mathrm{CSHCN}$ received during the last 12 months. The care coordination variable was named "carecoor" in the DRC database with categories: (a) Did not meet one or more care coordination elements; (b) Met all needed components of care coordination; (c) Legitimate skip (no help needed with care coordination). This variable was derived from the combination of respondents' parental response to several questions that addressed three main components: (a) if family received some type of help with care coordination; (b) family's satisfaction with communication among doctors and other providers if the child visited a specialist, received therapy, used mental health services, received substance abuse treatment, or used home health care services during the last 12 months; and (c) family's satisfaction with communication between doctors and other programs (e.g. school, day care, other programs) when such interactions were needed. Table 4 provides the care coordination specific questions:

Table 4

Specific Care Coordination Questions

\begin{tabular}{lc}
\hline \multicolumn{1}{c}{$\begin{array}{c}\text { Care Coordination (CC) individual item components } \\
\text { and questionnaire reference }\end{array}$} & $\begin{array}{c}\text { Response } \\
\text { categories }\end{array}$ \\
\hline C5Q12 & Yes \\
"Does anyone help you arrange or coordinate (S.C.)'s care among the & No \\
different doctors or services that (he/she) uses?” (2005-2006 NS- & \\
CSHCN, Section 5, Care Coordination, p.51) & Yes \\
\hline C5Q17 & No \\
'(During the past 12 months/ Since (his/her) birth), have you felt that & \\
you could have used extra help arranging or coordinating (S.C.)'s care & \\
NS-CSHCN, Section 5, Care Coordination, p.52) & \\
\hline
\end{tabular}




\begin{tabular}{|c|c|}
\hline $\begin{array}{l}\text { Care Coordination (CC) individual item components } \\
\text { and questionnaire reference }\end{array}$ & $\begin{array}{l}\text { Response } \\
\text { categories }\end{array}$ \\
\hline $\begin{array}{l}\text { C5Q09 } \\
\text { "(During the past } 12 \text { months/ Since (his/her) birth), how often did you get } \\
\text { as much help as you wanted with arranging or coordinating (S.C.)'s care? } \\
\text { Would you say never, sometimes, or usually?" (2005-2006 NS-CSHCN, } \\
\text { Section 5, Care Coordination, p.52) }\end{array}$ & $\begin{array}{c}\text { Never } \\
\text { Sometimes } \\
\text { Usually }\end{array}$ \\
\hline $\begin{array}{l}\text { C5Q10 } \\
\text { "Overall, are you very satisfied, somewhat satisfied, somewhat } \\
\text { dissatisfied, or very dissatisfied with the communication among (S.C.)'s } \\
\text { doctors and other health care providers?" (2005-2006 NS-CSHCN, } \\
\text { Section 5, Care Coordination, p.52) }\end{array}$ & $\begin{array}{c}\text { Very satisfied } \\
\text { Somewhat } \\
\text { satisfied } \\
\text { Somewhat } \\
\text { dissatisfied } \\
\text { Very } \\
\text { dissatisfied } \\
\end{array}$ \\
\hline $\begin{array}{l}\text { C5Q05 } \\
\text { "Do (S.C.)'s doctors or other health care providers need to communicate } \\
\text { with (his/her) school, early intervention program, child care providers, } \\
\text { vocational education or rehabilitation program?" (2005-2006 NS- } \\
\text { CSHCN, Section 5, Care Coordination, p.52) }\end{array}$ & $\begin{array}{l}\text { Yes } \\
\text { No }\end{array}$ \\
\hline $\begin{array}{l}\text { C5Q06 } \\
\text { "Overall, are you very satisfied, somewhat satisfied, somewhat } \\
\text { dissatisfied, or very dissatisfied with that communication?" (2005-2006 } \\
\text { NS-CSHCN, Section 5, Care Coordination, p.53). }\end{array}$ & $\begin{array}{c}\text { Very satisfied } \\
\text { Somewhat } \\
\text { satisfied } \\
\text { Somewhat } \\
\text { dissatisfied } \\
\text { Very } \\
\text { dissatisfied }\end{array}$ \\
\hline $\begin{array}{l}\text { C4Q05_X02, C4Q05X02C } \\
\text { "During the past } 12 \text { months was there any time when (S.C.) needed care } \\
\text { from a specialty doctor?" or "Did (S.C.) get any care from a specialty } \\
\text { doctor during the last } 12 \text { months?" (2005-2006 NS-CSHCN, Section 4, } \\
\text { Access to care, p.47). }\end{array}$ & $\begin{array}{l}\text { Yes } \\
\text { No }\end{array}$ \\
\hline $\begin{array}{l}\text { C4Q05_X05A, C4Q05X05C } \\
\text { "During the past } 12 \text { months was there any time when (S.C.) needed } \\
\text { physical, occupational or speech therapy?" or "Did (S.C.) get any } \\
\text { physical, occupational or speech therapy during the last } 12 \text { months?" } \\
\text { (2005-2006 NS-CSHCN, Section 4, Access to care, p.39). }\end{array}$ & $\begin{array}{l}\text { Yes } \\
\text { No }\end{array}$ \\
\hline $\begin{array}{l}\text { C4Q05_X06, C4Q05X06C } \\
\text { "During the past } 12 \text { months was there any time when (S.C.) needed } \\
\text { mental health care or counseling?" or "Did (S.C.) get any mental health } \\
\text { care or counseling during the last } 12 \text { months?" (2005-2006 NS-CSHCN, } \\
\text { Section 4, Access to care: utilization and unmet needs, p.40). }\end{array}$ & $\begin{array}{l}\text { Yes } \\
\text { No }\end{array}$ \\
\hline
\end{tabular}

(table continues) 


\begin{tabular}{|c|c|}
\hline $\begin{array}{l}\text { Care Coordination (CC) individual item components } \\
\text { and questionnaire reference }\end{array}$ & $\begin{array}{l}\text { Response } \\
\text { categories }\end{array}$ \\
\hline $\begin{array}{l}\text { C4Q05_X07, C4Q05_X07C } \\
\text { "During the past } 12 \text { months there any time when (S.C.) needed substance } \\
\text { abuse treatment or counseling?" or "Did (S.C.) get any substance abuse } \\
\text { treatment or counseling during the last } 12 \text { months? (for children above } 8 \\
\text { years of age)" ( } 2005-2006 \text { NS-CSHCN, Section 4, Access to care: } \\
\text { utilization and unmet needs, p.41). }\end{array}$ & $\begin{array}{l}\text { Yes } \\
\text { No }\end{array}$ \\
\hline $\begin{array}{l}\text { C4Q05_X08, C4Q05X08C } \\
\text { "During the past } 12 \text { months there any time when (S.C.) needed home } \\
\text { health care?" (for children above } 8 \text { years of age) or "Did (S.C.) get any } \\
\text { home health care during the last } 12 \text { months?" (2005-2006 NS-CSHCN, } \\
\text { Section 4, Access to care, p.42). }\end{array}$ & $\begin{array}{l}\text { Yes } \\
\text { No }\end{array}$ \\
\hline $\begin{array}{l}\text { C4Q05X02A, C4Q05X02C } \\
\text { "Did (S.C.) receive all the care from a specialist doctor that (he/she) } \\
\text { needed? or Did (S.C.) gets any care from a specialty doctor during the } \\
\text { past } 12 \text { months?" (2005-2006 NS-CSHCN, Section 4, Access to care: } \\
\text { utilization and unmet needs, p.35). }\end{array}$ & \\
\hline $\begin{array}{l}\text { C4Q05X05A, C4Q05X05C } \\
\text { "Did (S.C) receive all the therapy that (he/she) needed or Did (S.C.) get } \\
\text { any therapy during the past } 12 \text { months?" (2005-2006 NS-CSHCN, } \\
\text { Section 4, Access to care: utilization and unmet needs, p.39). }\end{array}$ & $\begin{array}{l}\text { Yes } \\
\text { No }\end{array}$ \\
\hline $\begin{array}{l}\text { C4Q05X06A, C4Q05X06C } \\
\text { "Did (S.C) receive all the mental health or counseling that (he/she) } \\
\text { needed? or Did (S.C.) get any mental health or counseling during the past } \\
12 \text { months?" (2005-2006 NS-CSHCN, Section 4, Access to care: } \\
\text { utilization and unmet needs, p.40). }\end{array}$ & $\begin{array}{l}\text { Yes } \\
\text { No }\end{array}$ \\
\hline $\begin{array}{l}\text { C4Q05X08A, C4Q05X08C } \\
\text { "Did (S.C) receive all the home health care that (he/she) needed? or Did } \\
\text { (S.C.) gets any home health care during the past } 12 \text { months?" (2005-2006 } \\
\text { NS-CSHCN, Section 4, Access to care: utilization and unmet needs, } \\
\text { p.42). }\end{array}$ & $\begin{array}{l}\text { Yes } \\
\text { No }\end{array}$ \\
\hline $\begin{array}{l}\text { C5Q10 } \\
\text { "Overall, are you very satisfied, somewhat satisfied, somewhat } \\
\text { dissatisfied, or very dissatisfied with the communication among (S.C.)'s } \\
\text { doctors and other health care providers?" (2005-2006 NS-CSHCN, } \\
\text { Section 5, Care Coordination, p.52) }\end{array}$ & $\begin{array}{c}\text { Very satisfied } \\
\text { Somewhat } \\
\text { satisfied } \\
\text { Somewhat } \\
\text { dissatisfied } \\
\text { Very } \\
\text { dissatisfied } \\
\end{array}$ \\
\hline
\end{tabular}

Note. (S.C.) refers to Sampled Child. 
Syntax details on how to arrive to this indicator are specified in the 2005-2006

National Survey of CSHCN SPSS Codebook (CAHMI, 2008). Table 5 provides

information on how these questions were combined to measure care coordination:

Table 5

Algorithm to Combine Care Coordination Questions

\begin{tabular}{|c|c|}
\hline Care coordination components & Combination \\
\hline Received care help (carehelp) & $\begin{array}{l}\text { Anyone helped family arrange or coordinate child's } \\
\text { care among different doctors } \\
\text { AND } \\
\text { the family SOMETIMES/USUALLY received help } \\
\text { in coordinating care } \\
\text { OR } \\
\text { Legitimate skip because child received less than } 2 \\
\text { services or did not receive help } \\
\text { AND }\end{array}$ \\
\hline $\begin{array}{l}\text { Family's satisfaction with } \\
\text { communication among doctors } \\
\text { when child received a service } \\
\text { (drcomm) }\end{array}$ & $\begin{array}{l}\text { Child received ALL OR SOME of any of the } \\
\text { following services: } \\
\text { specialist, therapy, mental health services, substance } \\
\text { abuse treatment, home health care services } \\
\text { AND } \\
\text { Family was VERY SATISFIED with the doctor to } \\
\text { doctor communication } \\
\text { OR } \\
\text { Legitimate skip because the child did not use any of } \\
\text { above services or communication was not needed } \\
\text { AND }\end{array}$ \\
\hline $\begin{array}{l}\text { Family's satisfaction with } \\
\text { communication between doctors } \\
\text { and other programs (othercomm) }\end{array}$ & $\begin{array}{l}\text { Child's doctors or other health care providers } \\
\text { communicated with the child school, early } \\
\text { intervention program, health care providers, } \\
\text { vocational or rehabilitation programs } \\
\text { AND } \\
\text { Family was VERY SATISFIED with } \\
\text { communication between doctors and other child's } \\
\text { programs } \\
\text { OR } \\
\text { Legitimate skip because child used less than } 2 \\
\text { services }\end{array}$ \\
\hline
\end{tabular}


The other main independent variable included in this study was family-centered care. It is named "indic11_05" in the DRC dataset with response categories: (a) Does not have family centered care; (b) Have family centered care. This variable is derived from the responses to six survey questions that were combined to determine if child received family-centered care. The questions addressed if health care providers: spent enough time with the child, listened carefully to the parents, made parents feel like a partner in their child's care, were sensitive to the family's customs and values, provided the specific information that the parent needed. An additional question was included to determine if families obtained interpreter services when needed. Table 6 specifies the survey questions used to assess receipt of family-centered care (S.C. refers to sampled child's name or initials):

Table 6

Specific Family-Centered Care Questions

\begin{tabular}{|c|c|}
\hline $\begin{array}{c}\text { Family-Centered Care (FCC) individual item components } \\
\text { and questionnaire reference }\end{array}$ & Response categories \\
\hline $\begin{array}{l}\text { C6Q02 } \\
\text { "(During the past } 12 \text { months/ [WHEN S.C. IS YOUNGER THAN } 12 \\
\text { MONTHS] Since (his/her) birth), how often did (S.C.)'s doctors and } \\
\text { other health care providers spend enough time with (him/her)? Would } \\
\text { you say never, sometimes, usually, or always?" (2005-2006 NS-CSHCN, } \\
\text { Section 6A, Family-Centered Care, p.53) }\end{array}$ & $\begin{array}{c}\text { Never } \\
\text { Sometimes } \\
\text { Usually } \\
\text { Always }\end{array}$ \\
\hline $\begin{array}{l}\text { C6q03 } \\
\text { "(During the past } 12 \text { months/ [WHEN S.C. IS YOUNGER THAN } 12 \\
\text { MONTHS] Since (his/her) birth), how often did (S.C.)'s doctors and } \\
\text { other health care providers listen carefully to you? Would you say never, } \\
\text { sometimes, usually, or always?" (2005-2006 NS-CSHCN, Section 6A, } \\
\text { Family-Centered Care, p.53) }\end{array}$ & $\begin{array}{c}\text { Never } \\
\text { Sometimes } \\
\text { Usually } \\
\text { Always }\end{array}$ \\
\hline $\begin{array}{l}\text { C6q04 } \\
\text { "When (S.C.) is seen by doctors or other health care providers, how often } \\
\text { are they sensitive to your family's values and customs? Would you say } \\
\text { never, sometimes, usually, or always?" (2005-2006 NS-CSHCN, Section } \\
6 \text { A, Family-Centered Care, p.53) }\end{array}$ & $\begin{array}{c}\text { Never } \\
\text { Sometimes } \\
\text { Usually } \\
\text { Always }\end{array}$ \\
\hline
\end{tabular}




\begin{tabular}{lc}
\hline \multicolumn{1}{c}{$\begin{array}{c}\text { Family-Centered Care (FCC) individual item components } \\
\text { and questionnaire reference }\end{array}$} & $\begin{array}{c}\text { Response } \\
\text { categories }\end{array}$ \\
\hline $\begin{array}{l}\text { C6q05 } \\
\text { "Information about a child's health or health care can include things such as } \\
\text { the causes of any health problems, how to care for a child now, and what } \\
\text { changes to expect in the future. [In the past 12 months/ [WHEN S.C. IS }\end{array}$ & $\begin{array}{c}\text { Never } \\
\text { Sometimes } \\
\text { Usually }\end{array}$ \\
$\begin{array}{l}\text { YOUNGER THAN 12 MONTHS] Since (his/her) birth], how often did you } \\
\text { care providers? Would you say never, sometimes, usually, or always?" (2005- }\end{array}$ & Always \\
2006 NS-CSHCN, Section 6A, Family-Centered Care, p.54) & \\
\hline $\begin{array}{l}\text { C6q06 } \\
\text { "(During the past 12 months/ [WHEN S.C. IS YOUNGER THAN 12 }\end{array}$ & \\
MONTHS] Since (his/her) birth), how often did (S.C.)'s doctors or other \\
$\begin{array}{l}\text { health care providers help you feel like a partner in (his/her) care? Would you } \\
\text { say never, sometimes, usually, or always?" (2005-2006 NS-CSHCN, Section }\end{array}$ & Sometimes \\
6A, Family-Centered Care, p.54) & Usually \\
\hline $\begin{array}{l}\text { S5Q13A } \\
\text { "When you (or S.C.) needed an interpreter, how often were you able to get }\end{array}$ \\
$\begin{array}{l}\text { someone other than a family member to help you speak with (his/her) doctors } \\
\text { or other health care providers? Would you say never, sometimes, usually, or } \\
\text { always?" (2005-2006 NS-CSHCN, Section 6A, Family-Centered Care, p.54) }\end{array}$ \\
\begin{tabular}{l} 
Sometimes \\
\hline
\end{tabular}
\end{tabular}

Note. (S.C.) refers to Sampled Child.

Details of the syntax to combine questions are provided in the 2005-2006 National Survey of CSHCN SPSS Codebook (CAHMI, 2008). Table 7 provides information on how these questions were combined to measure family-centered care components (S.C. refers to sampled child):

Table 7

Algorithm to Combine Family-Centered Care Questions

FCC components Combination

Doctors and health providers spend Doctors and health providers time with the child (time) $\quad$ USUALLY/ALWAYS spent time with the child OR

Respondent did not know or refused to answer the question

AND

(table continues) 


\begin{tabular}{|c|c|}
\hline FCC components & Combination \\
\hline \multirow{5}{*}{$\begin{array}{l}\text { Doctors and health providers listen } \\
\text { carefully to the parents (listen) }\end{array}$} & Doctors and health providers \\
\hline & $\begin{array}{l}\text { USUALLY/ALWAYS listened carefully to the } \\
\text { family }\end{array}$ \\
\hline & OR \\
\hline & $\begin{array}{l}\text { Respondent did not know or refused to answer the } \\
\text { question }\end{array}$ \\
\hline & AND \\
\hline \multirow{5}{*}{$\begin{array}{l}\text { Doctors and health providers are } \\
\text { sensitive to the family's customs } \\
\text { and values (sensitive) }\end{array}$} & Doctors and health providers were \\
\hline & \\
\hline & OR \\
\hline & $\begin{array}{l}\text { Respondent did not know or refused to answer the } \\
\text { question }\end{array}$ \\
\hline & AND \\
\hline \multirow{5}{*}{$\begin{array}{l}\text { Doctors and health providers } \\
\text { provide the specific information that } \\
\text { the parent needs (info) }\end{array}$} & Doctors and health providers \\
\hline & $\begin{array}{l}\text { USUALLY/ALWAYS provided specific } \\
\text { information that the family needed }\end{array}$ \\
\hline & \\
\hline & $\begin{array}{l}\text { Respondent did not know or refused to answer the } \\
\text { question }\end{array}$ \\
\hline & AND \\
\hline \multirow{5}{*}{$\begin{array}{l}\text { Doctors and health providers help } \\
\text { family feel like a partner in care } \\
\text { (partner) }\end{array}$} & Doctors and health providers \\
\hline & $\begin{array}{l}\text { USUALLY/ALWAYS helped family feel like a } \\
\text { partner in the child care }\end{array}$ \\
\hline & OR \\
\hline & $\begin{array}{l}\text { Respondent did not know or refused to answer the } \\
\text { question }\end{array}$ \\
\hline & AND \\
\hline \multirow[t]{3}{*}{$\begin{array}{l}\text { Families obtained interpreter } \\
\text { services when needed (interpret) }\end{array}$} & $\begin{array}{l}\text { Family USUALLY/ALWAYS was able to get } \\
\text { someone other than a family member to help the } \\
\text { family speak with the child doctors or other health } \\
\text { care providers (when needed) }\end{array}$ \\
\hline & OR \\
\hline & $\begin{array}{l}\text { Respondent did not need interpreter services or did } \\
\text { not know or refused to answer the question }\end{array}$ \\
\hline
\end{tabular}

This study also included other variables or covariates, including age, gender, race, number of health conditions, household's poverty level, household's educational level, health insurance coverage and type of health insurance. Age referred to the child's age in 
years at the time of interview. Gender was represented by two categories: male or female. Race variable was represented in dataset as "race_5" with categories of Hispanics, non-Hispanic Whites, non-Hispanic Blacks/African American only, multiracial, and other. The multiracial category refers to children of more than one race category. The "other race" category includes three groups: Asian, Native American/Alaska Native, and Native Hawaiian/Other Pacific Islander (CDC, 2008). Four dummy variables coded $0 / 1$ were created to analyze this variable in multivariate models.

Number of health conditions was a derived variable based on the count of positive responses to 16 condition-specific questions. This variable was included in the DRC dataset as "cond_5" with categories of (a) none reported condition; (b) 1 reported condition; (c) 2 reported conditions; (d) 3 reported conditions; (e) 4 or more reported conditions. Dummy variables were created to analyze this variable.

Household poverty level was a derived variable that referred to how many CHSCN live in households at different levels of income according to the federal poverty guidelines (FPL) (CDC, 2008). This variable was calculated based on the answers to the questions of how many people are living in the household and total combined household income for the past year. This income index is based on the Department of Health and Human Services 2005-2006 Federal Poverty Guidelines (FPL). Categories for this variable were (a) Percent of CSHCN living in households with income below 100\%; (b) 100-199\%; (c) 200-399\%; (d) 400\% or more of Federal Poverty Level (FPL) according to family size. If data for either of these two questions were missing or responses were 
refused, or had a “don't know” response, the household poverty level variable was assigned a missing code. Dummy variables were created to analyze this variable.

Household educational level was a derived variable based on the responses to the question: "What is the highest level of school that anyone in the household has completed or the highest degree anyone in the household has received?" (2005-2006 NS-CSHCN Section 2. Initial Screening, p. 17) with response categories of (a) $8^{\text {th }}$ grade or less; (b) $9^{\text {th }}-12^{\text {th }}$ grade; (c) high school graduate or GED; (d) some college (less than 4 years); (e) college graduate $(4+$ years). The responses to this variable were combined to produce three main categories: (a) Less than high school; (b) High school graduate; (c) More than high school. Two dummy variables coded $0 / 1$ were created to analyze this variable in logistic regression.

Another variable that was analyzed in this study was health insurance coverage, this is, if the child was currently insured or not at the time of the survey. This variable was included in the public use data file and is named "UNINS". This variable was derived by the National Center for Health Statistics from responses to health insurance coverage questions asked in Section 7 of the National Survey of CSHCN's questionnaire (CDC, 2008). This section provided information to determine if children had comprehensive health insurance coverage that covered costs for both doctor visits and hospitalizations. The section also included questions on types of health insurance, if there was a time where the child lacked health insurance during the previous 12 months and how long was without insurance (CDC, 2008). These insurance questions were validated during the implementation of the first 2001-2002 NS-CSHCN (Blumberg, Osborn, Luke et al., 2004). 
Another variable that was included in the study was type of health insurance named as "TYPEINS" in the database with the following categories: (a) private only; (b) public only; (c) both public and private; (d) other comprehensive insurance; (e) uninsured. Private insurance was determined by responding "YES" to any of the following questions: (a) "Now I have a few questions about health insurance and health care coverage for (S.C.). At this time, is (S.C.) covered by health insurance that is provided through an employer or union?” (2005-2006 NS-CSHCN Section 7 Health Insurance, p. 64); (b) "Is this health insurance provided through an employer or union?" asked when respondent answered having other comprehensive health insurance (20052006 NS-CSHCN Section 7. Health Insurance, p. 67); (c) "Does (S.C.) has any other kind of health coverage?"/ ELSE FILL "At this time, what kind of health coverage does (S.C.) have? Any other kind?” (2005-2006 NS-CSHCN Section 7 Health Insurance, p. 68) with a YES/NO response options to health insurance types: Medicaid, Medicare, SCHIP, Medigap, Military, Indian Health Service, Private Insurance, Single service plan, and other; (d) "Does this health insurance help pay for both doctor visits and hospital stays?" (2005-2006 NS-CSHCN Section 7 Health Insurance, p. 68). Dummy variables were created to analyze this variable in multivariate logistic regression.

\section{Hypotheses}

In this study, two hypotheses were evaluated:

$H 1_{0}$ : Care coordination is not associated with the ability of CSHCN to perform activities that most children of the same age can do generally.

$H 1_{\mathrm{A}}$ : Care coordination is associated with the ability of $\mathrm{CSHCN}$ to perform activities that most children of the same age can do generally. 
$H 2_{0}$ : Family-centered care is not associated with the ability of CSHCN to perform activities that most children of the same age can do generally.

$H 2_{\mathrm{A}}$ : Family-centered care is associated with the ability of CSHCN to perform activities that most children of the same age can do generally. These hypotheses were evaluated controlling for other variables.

\section{Data Analysis Methods}

The following section provides information on aspects to consider in the management and analysis of the 2005-2006 NS-CSHCN database. This section also discusses the statistical methods that were used to analyze the data. This section begins with a discussion of the statistical analysis software that was used to analyze the data considering the complex sample design of the survey, followed by a discussion of sampling weights and variance estimation issues. The section also presents the statistical analysis methods that were used to analyze data followed by a discussion on measures to protect survey participants' rights and data confidentiality.

\section{Statistical Analysis Software}

The sampling design of the $2005-2006$ NS-CSHCN is a complex one. The CDC (2008) recommends using statistical software that considers complex sample designs in order to calculate variances, standard errors and confidence intervals in hypothesis testing. This is because statistical software that uses simple random sampling arrives to standards errors that are low, which may result in misleading results from tests of statistical hypotheses. CDC recommends particular computer programs such as SUDAAN, SAS V 9.0+, STATA, WesVar, and SPSS Complex Samples to analyze data from the NS-CSHCN (CDC, 2008). For the purposes of this study, I used STATA/IC 
version 11.0 to analyze data accounting for the complex sample design and weighting methods. The database includes primary sampling unit (PSU) codes, stratum identifiers, and sample weights that were used to estimate complex sample variances.

\section{Sampling Weights}

Sampling weights were necessary in order to obtain estimates representative of the population of non-institutionalized children with special needs less than 18 years of age at the national and state levels. The database contained the weighting variable WEIGHT_I that adjusted the survey responses to reflect the underlying CSHCN population less than 18 years of age in each state and the District of Columbia based on the US Census counts of children stratified by sociodemographic characteristics, including age, sex, and race/ethnicity (CDC, 2008).

\section{Statistical Analysis Methods}

Data were analyzed using univariate, bivariate, and multivariate statistical methods. These methods required variables to be recoded to collapse categories or combined with other variables in the construct of complex variables. Response categories of "Don't know" and "Refused" were considered as missing values in this study. Pearson design-based F-test was used to analyze categorical data. Multiple logistic regression analysis techniques were used to explore associations between the dependent variable and independent variables. Sample weights were included in all estimates.

Univariate methods included descriptive statistics, such as, distributions of frequencies, percentages and confidence intervals. Descriptive statistics were presented 
in a table format, including sociodemographic variables (age, gender) and other study variables. These statistics included the number of study subjects (n), population estimates, weighted percentages and 95\% confidence intervals. Calculations of mean, standard deviation and 95\% confidence intervals were made for the continuous variable of age. Table 8 provides a list of specific types of data analyzed in the study.

Table 8

\section{Study Variables}

\begin{tabular}{|c|c|c|}
\hline Type of data & Specific data element & Type of variable \\
\hline $\begin{array}{l}\text { Functional ability } \\
\text { (CSHCN3) }\end{array}$ & $\begin{array}{l}\text { Child with limitation in functional } \\
\text { ability (functional limitation) } \\
\text { Child with no limitation in functional } \\
\text { ability }\end{array}$ & $\begin{array}{l}\text { Dependent } \\
\text { variable }\end{array}$ \\
\hline Care-coordination (CC) & $\begin{array}{l}\text { Derived variable with two response } \\
\text { categories: } \\
\text { Met all CC components (Yes) } \\
\text { Did not meet one or more CC } \\
\text { components (No) }\end{array}$ & $\begin{array}{l}\text { Independent } \\
\text { variable }\end{array}$ \\
\hline $\begin{array}{l}\text { Family-centered care } \\
\text { (FCC) }\end{array}$ & $\begin{array}{l}\text { Derived variable with two response } \\
\text { categories: } \\
\text { Met all FCC components (Yes) } \\
\text { Did not meet one or more FCC } \\
\text { components (No) }\end{array}$ & $\begin{array}{l}\text { Independent } \\
\text { variable }\end{array}$ \\
\hline Sociodemographic data & $\begin{array}{l}\text { Gender: Male, Female } \\
\text { Age (Numeric variable) } \\
\text { Race (White, Black, Hispanic, } \\
\text { Multirace, Other) }\end{array}$ & $\begin{array}{l}\text { Covariate } \\
\text { Covariate } \\
\text { Covariate }\end{array}$ \\
\hline $\begin{array}{l}\text { Number of health } \\
\text { conditions }\end{array}$ & $\begin{array}{l}1,2,3 \text { or } 4 \text { or more reported } \\
\text { conditions }\end{array}$ & Covariate \\
\hline Household poverty level & $\begin{array}{l}<100 \%, \\
100-199 \% \\
200-399 \%, \\
400 \% \text { or more }\end{array}$ & Covariate \\
\hline $\begin{array}{l}\text { Household educational } \\
\text { level }\end{array}$ & $\begin{array}{l}\text { Less than high school } \\
\text { High school graduate } \\
\text { More than high school }\end{array}$ & Covariate \\
\hline
\end{tabular}




\begin{tabular}{lll}
\hline Type of data & Specific data element & Type of variable \\
\hline Health insurance & Yes & Covariate \\
\hline Nype of health insurance & $\begin{array}{l}\text { Public, Private, Both public and } \\
\text { private, Other insurance }\end{array}$ & Covariate \\
\hline
\end{tabular}

Bivariate analysis included cross-tabulations and the Pearson design-based F test statistical significance test. Bivariate statistics were used to make comparisons for demographic and condition characteristics, main independent variables, and covariates in relation to $\mathrm{CSHCN}$ functionality. Weighted percentages, $95 \%$ confidence intervals and p-values were presented in a table for each variable for three main groups: (a) CSHCN in general, (b) CSHCN with limitation in functional ability, and (c) CSHCN with no limitation in functional ability.

Multivariate logistic regression analysis was used to evaluate study hypotheses and to calculate odds ratios. The analysis helped to determine which factors were associated with functional ability in CSHCN. Primary independent variables were care coordination and family-centered care. Individual logistic regression models were developed to evaluate the association between the dependent variable and each independent variable adjusting by potential confounders (covariates). A complete logistic regression model that includes all variables was also developed to obtain estimated unadjusted and adjusted odds ratios (ORaj) for the studied variables. An additional analysis was done with a sample of children with a specific health condition to determine if there was any difference between CSHCN in general and by condition. An alpha level of 0.05 for $p$-values and $95 \%$ confidence intervals were used to assess the 
strength of association between independent and dependent variables. Regression models were controlled for demographic characteristics and other covariates.

The multivariate analysis methods included the weighting variable (WEIGHT_I) assigned to each child with special needs based on sociodemographic characteristics. Other weighting variables needed as part of analyses in order to obtain complex sample variances and standard errors and that were included in the database were stratum identifiers and primary sample unit (PSU) codes. The stratum identifier was the STATE. The PSU for the NS-CSHCN corresponded to the household and was represented on the data sets by an individual household identifier "IDNUMR". Standard errors were computed in STATA using the Taylor-series approximation method because the PSU's were sampled with replacement in the survey (CDC, 2008).

\section{Measures to Protect Participants' Rights}

The design and operation of the 2005-2006 NS-CSHCN survey contemplated ways to obtain an informed consent from participants and protect the identity and confidentiality of the information. The informed consent was orally obtained from participants after the interviewer explained the study purpose to the participant, informed them that participation in the survey was voluntary, assured that responses were confidential and that there was no penalty for refusing to answer any question. Each participant's verbal consent was registered in the CATI system (Blumberg et al., 2007).

Mechanisms to protect confidentiality were needed due to the size of the survey sample and the amount and type of collected information. Strategies used to protect confidentiality included suppressing particular survey variables and grouping response categories. Protected variables included geographic location, race, family structure, 
number of children in the household, date of birth, and income. The study can be considered of minimal risk because it does not affect participants' welfare and there are many benefits that can be obtained from the study, especially information to assess met and unmet needs of children, how is health affected and health care areas that can be improved based on survey information. Data were reported in this study in an aggregated statistical form, which helps in protecting confidentiality of data. The Institutional Review Board at the National Center for Health Statistics and the NORC Institutional Review Board at the University of Chicago approved the 2005-2006 NS-CSHCN before its implementation (CDC, 2008).

The database used in this study did not contain identifying personal information. Additionally, data were reported in an aggregated statistical form. The documentation for the present study includes the DRC data use agreement form and approval. Only the investigator had access to the database as an additional way to protect the information. The study proposal was submitted and approved by the Institute Review Board (IRB) of Walden University (approval number 12-15-10-0359282) prior to analysis and reporting. 


\section{Chapter 4: Results}

This chapter presents the results from statistical analyses, beginning with descriptive and bivariate statistics followed by multiple logistic regression analysis models. Research questions and hypotheses evaluated in this study were the following:

Research question 1: Is care coordination associated with the ability of CSHCN to perform activities that most children of the same age can perform generally, including physical and/or mental activities, adjusting for other variables?

$\mathrm{H}_{0}$ : Care coordination is not associated with the ability of CSHCN to perform activities that most children of the same age can perform generally.

$\mathrm{H} 1_{\mathrm{A}}$ : Care coordination is associated with the ability of CSHCN to perform activities that most children of the same age can perform generally.

Research question 2: Is family-centered care associated with the ability of CSHCN to perform activities that most children of the same age can perform generally, including physical and/or mental activities, adjusting for other variables?

$\mathrm{H} 2_{0}$ : Family-centered care is not associated with the ability of CSHCN to perform activities that most children of the same age can perform generally.

$\mathrm{H} 2_{\mathrm{A}}$ : Family-centered care is associated with the ability of CSHCN to perform activities that most children of the same age can perform generally.

\section{Descriptive Characteristics}

A total of 40,723 participants responded to the 2005-2006 National Survey of Children with Special Health Care Needs (NS-CSHCN). A sample of 6,850 cases was randomly selected for the study. Cases with missing data were deleted from the analysis. 
The final sample size for analysis was 4,977, representing approximately 1,261,212 CSHCN in the US. The .svyset command was used to establish the complex sample design of the survey before beginning data analysis in STATA. The stratum identifier was the "STATE" and the primary sample unit (PSU) was the household represented by the variable "IDNUMR". Results were weighted to represent the general CSHCN population.

Tables 9 through 11 provide data on the distribution of demographic characteristics of CSHCN and by functional limitation using univariate and bivariate analysis. The prevalence of limitation in functional ability in CSHCN was $27.1 \%$ (95\%CI 25.0 - 29.2). Mean age of CSHCN was 10 years approximately. Most CSHCN were males $(60.8 \%, 95 \%$ CI 58.6-63.0) and White-non Hispanics $(66 \%, 95 \%$ CI 63.5 68.1). No statistical differences were found in functional limitation by gender or race. In terms of number of conditions, most children had one or two conditions $(31 \%), 16 \%$ had three conditions and $13 \%$ had four or more conditions. There was a statistically significant difference in functional limitation by number of health conditions $(p<0.01)$.

Table 9

Percent of CSHCN by Limitation in Functional Ability $(n=4,977)$

\begin{tabular}{ccc}
\hline $\begin{array}{c}\text { Limitation in } \\
\text { functional ability }\end{array}$ & Weighted percent & $\begin{array}{c}95 \% \text { Confidence } \\
\text { Interval }\end{array}$ \\
\hline Yes & 27.1 & $25.0-29.2$ \\
\hline No & 73.0 & $70.8-75.0$ \\
\hline
\end{tabular}

Table 10 presents the results of the mean age of CSHCN in general and by limitation in functional ability. 
Table 10

Mean Age of Children with Special Health Care Needs $(n=4,977)$

\begin{tabular}{ccc}
\hline $\begin{array}{c}\text { Mean age } \\
\text { (weighted) }\end{array}$ & \multicolumn{2}{c}{$\begin{array}{c}\text { Weighted mean age by limitation in } \\
\text { functional ability }(95 \% \mathrm{CI}) \\
\text { Yes }\end{array}$} \\
\hline 9.8 & 9.8 & No \\
$(9.6-10.0)$ & $(9.3-10.3)$ & $(9.5-10.1)$ \\
\hline
\end{tabular}

Table 11

Child-Level Characteristics of CSHCN in General and by Limitation in Functional Ability $(n=4,977)$

\begin{tabular}{|c|c|c|c|c|c|}
\hline \multirow[t]{2}{*}{ Characteristic } & \multirow[t]{2}{*}{$\begin{array}{l}\text { CSHCN in } \\
\text { general } \\
\text { Weighted \% } \\
(95 \% \mathrm{CI})\end{array}$} & \multicolumn{2}{|c|}{$\begin{array}{l}\text { Limitation in } \\
\text { Functional } \\
\text { Ability } \\
\text { Weighted \% }\end{array}$} & \multirow[t]{2}{*}{$\begin{array}{c}\text { Pearson } \\
\text { design- } \\
\text { based F } \\
\text { test }\end{array}$} & \multirow[t]{2}{*}{$\begin{array}{c}\mathrm{p} \\
\text { value }\end{array}$} \\
\hline & & No & Yes & & \\
\hline \multicolumn{6}{|l|}{ Gender } \\
\hline Female & $\begin{array}{c}39.2 \\
(37.0-41.4)\end{array}$ & 29.0 & 10.3 & \multirow[t]{2}{*}{0.5243} & \multirow[t]{2}{*}{0.47} \\
\hline Male & $\begin{array}{c}60.8 \\
(58.6-63.0)\end{array}$ & 44.0 & 17.0 & & \\
\hline \multicolumn{6}{|l|}{ Race } \\
\hline White non-Hispanics & $\begin{array}{c}66.0 \\
(63.5-68.1)\end{array}$ & 48.3 & 17.6 & \multirow{5}{*}{0.6154} & \multirow{5}{*}{0.65} \\
\hline Hispanics & $\begin{array}{c}10.9 \\
(9.3-12.5)\end{array}$ & 7.6 & 3.3 & & \\
\hline Black non-Hispanics & $\begin{array}{c}15.8 \\
(13.9-17.7)\end{array}$ & 11.2 & 4.5 & & \\
\hline $\begin{array}{l}\text { Multiracial non- } \\
\text { Hispanic }\end{array}$ & $\begin{array}{c}4.6 \\
(3.5-5.6)\end{array}$ & 3.6 & 1.0 & & \\
\hline Other non-Hispanic & $\begin{array}{c}2.9 \\
(2.2-3.8)\end{array}$ & 2.3 & 0.7 & & \\
\hline \multicolumn{6}{|l|}{$\begin{array}{l}\text { Number of health } \\
\text { conditions* }\end{array}$} \\
\hline None & $\begin{array}{c}9.2 \\
(7.7-10.6)\end{array}$ & 7.9 & 1.3 & \multirow{3}{*}{53.5933} & \multirow{3}{*}{$<0.01$} \\
\hline 1 condition & $\begin{array}{c}31.1 \\
(28.9-33.3)\end{array}$ & 25.5 & 5.6 & & \\
\hline 2 conditions & $\begin{array}{c}30.7 \\
(28.5-32.8)\end{array}$ & 24.2 & 6.5 & & \\
\hline
\end{tabular}

(table continues) 


\begin{tabular}{|c|c|c|c|c|c|}
\hline \multirow[t]{2}{*}{ Characteristic } & \multirow[t]{2}{*}{$\begin{array}{c}\text { CSHCN in } \\
\text { general } \\
\text { Weighted \% } \\
(95 \% \mathrm{CI})\end{array}$} & \multicolumn{2}{|c|}{$\begin{array}{l}\text { Limitation in } \\
\text { Functional } \\
\text { Ability } \\
\text { Weighted \% }\end{array}$} & \multirow[t]{2}{*}{$\begin{array}{l}\text { Pearson } \\
\text { design- } \\
\text { based F } \\
\text { test }\end{array}$} & \multirow[t]{2}{*}{$\begin{array}{c}\mathrm{p} \\
\text { value }\end{array}$} \\
\hline & & No & Yes & & \\
\hline 3 conditions & $\begin{array}{c}15.9 \\
(14.3-17.7)\end{array}$ & 10.8 & 5.2 & & \\
\hline 4 or more conditions & $\begin{array}{c}13.0 \\
(11.4-14.7)\end{array}$ & 4.6 & 8.4 & & \\
\hline
\end{tabular}

*Tests for difference in proportion among the groups were statistically significant $(p<$ 0.05). $\mathrm{p}$ values were determined with the Pearson design-based F test.

Table 12 provides data on the family-level characteristics of CSHCN. The highest percentage of CSHCN was observed in the $200-399 \%$ household poverty level $(30.7 \%)$, followed by the $400 \%$ level or higher $(28.8 \%)$, the $100-199 \%$ level $(22.9 \%)$ and the less than $100 \%$ level (17.6\%). A significant difference was observed in the percentage of functional limitation by household poverty level. A higher percentage of children with functional limitation were observed in households where the poverty level was less than $400 \%$. In contrast, the percent of children without a limitation in functional ability increased as the poverty level increased, from $11.3 \%$ in households with less than $100 \%$ poverty level up to $22.7 \%$ in households with a poverty level of $400 \%$ or higher. About $72.3 \%$ of CSHCN lived in a household where parents had an educational level beyond high school, followed by high school graduate level (22.1\%) and less than high school education level (5.6\%). A statistically significant difference was observed in the percentage of functional limitation by educational level. The percentage of CSHCN with a functional limitation increased with increasing household educational level. The highest percentage was observed in households where parents had an educational level beyond high school (17.4\%), followed by high school graduate level (7.8\%) and less than high school educational level (1.9\%). Interestingly, the percentage of CSHCN without a 
limitation in functional ability increased as the household educational level increased.

The percentage was highest in households where parents had an educational level beyond high school (54.8\%), followed by high school graduate educational level (14.4\%) and less than high school educational level (3.7\%).

Table 12

Family-Level Characteristics of CSHCN in General and by Limitation in Functional Ability $(n=4,977)$

\begin{tabular}{|c|c|c|c|c|c|}
\hline \multirow[t]{2}{*}{ Characteristic } & \multirow[t]{2}{*}{$\begin{array}{l}\text { CSHCN in general } \\
\text { Weighted \% } \\
(95 \% \mathrm{CI})\end{array}$} & \multicolumn{2}{|c|}{$\begin{array}{l}\text { Limitation in } \\
\text { Functional } \\
\text { Ability } \\
\text { Weighted \% }\end{array}$} & \multirow[t]{2}{*}{$\begin{array}{l}\text { Pearson } \\
\text { design- } \\
\text { based F } \\
\text { test }\end{array}$} & \multirow[t]{2}{*}{$\begin{array}{c}\mathrm{p} \\
\text { value }\end{array}$} \\
\hline & & No & Yes & & \\
\hline \multicolumn{6}{|l|}{ Household poverty level* } \\
\hline$<100 \%$ & $\begin{array}{c}17.6 \\
(15.7-19.5)\end{array}$ & 11.3 & 6.3 & \multirow{4}{*}{11.6667} & \multirow{4}{*}{$<0.01$} \\
\hline $100-199 \%$ & $\begin{array}{c}22.9 \\
(20.9-25.0)\end{array}$ & 15.1 & 7.8 & & \\
\hline $200-399 \%$ & $\begin{array}{c}30.7 \\
(28.5-32.8)\end{array}$ & 23.8 & 6.9 & & \\
\hline $400 \%$ or more & $\begin{array}{c}28.8 \\
(26.8-30.8)\end{array}$ & 22.7 & 6.1 & & \\
\hline \multicolumn{6}{|l|}{$\begin{array}{l}\text { Household educational } \\
\text { level* }\end{array}$} \\
\hline Less than high school & $\begin{array}{c}5.6 \\
(4.4-6.8)\end{array}$ & 3.7 & 1.9 & \multirow{3}{*}{9.0050} & \multirow{3}{*}{$<0.01$} \\
\hline High school graduate & $\begin{array}{l}\quad 22.1 \\
(20.1-24.2)\end{array}$ & 14.4 & 7.8 & & \\
\hline More than high school & $\begin{array}{c}72.3 \\
(70.0-74.5)\end{array}$ & 54.8 & $\begin{array}{c}17 . \\
4\end{array}$ & & \\
\hline
\end{tabular}

*Tests for difference in proportion among the groups were statistically significant $(\mathrm{p}<0.05)$. $\mathrm{p}$ values were determined with the Pearson design-based $\mathrm{F}$ test.

Table 13 provides data on the community-level characteristics of $\mathrm{CSHCN}$ in general and by functional limitation. Most CSHCN were insured at survey time $(97.8 \%)$ and had private health insurance (60.2\%). Approximately, $26.7 \%$ of CSHCN had public insurance, $9.0 \%$ had both public and private insurance, and $1.9 \%$ had other insurance. A 
statistically significant difference was found in functional limitation by type of health insurance $(p<0.01)$. Most children with a functional limitation had private health insurance (12.7\%), followed by public insurance (9.8\%), both public and private insurance (3.4\%) and other type of insurance $(0.4 \%)$. In contrast, a greater proportion of children without a functional limitation had private health insurance $(47.5 \%)$, public insurance $(16.9 \%)$, both public and private insurance $(5.5 \%)$, and other insurance $(1.5 \%)$.

Table 13

Community-Level Characteristics of CSHCN in General and by Limitation in Functional Ability $(n=4,977)$

\begin{tabular}{|c|c|c|c|c|c|}
\hline \multirow[t]{2}{*}{ Characteristic } & \multirow[t]{2}{*}{$\begin{array}{c}\text { CSHCN in } \\
\text { general } \\
\text { Weighted \% } \\
(95 \% \mathrm{CI})\end{array}$} & \multicolumn{2}{|c|}{$\begin{array}{l}\text { Limitation in } \\
\text { Functional } \\
\text { Ability } \\
\text { Weighted \% }\end{array}$} & \multirow[t]{2}{*}{$\begin{array}{c}\text { Pearson } \\
\text { design- } \\
\text { based F } \\
\text { test }\end{array}$} & \multirow[t]{2}{*}{$\begin{array}{c}\mathrm{p} \\
\text { value }\end{array}$} \\
\hline & & No & Yes & & \\
\hline \multicolumn{6}{|l|}{ Health insurance } \\
\hline No & $\begin{array}{c}2.2 \\
(1.6-2.9)\end{array}$ & 1.6 & 0.6 & \multirow{2}{*}{0.0525} & \multirow{2}{*}{0.82} \\
\hline Yes & $\begin{array}{c}97.8 \\
(97.1-98.4)\end{array}$ & 71.3 & 26.5 & & \\
\hline \multicolumn{6}{|l|}{ Type of health insurance* } \\
\hline Private & $\begin{array}{c}60.2 \\
(57.8-62.5)\end{array}$ & 47.5 & 12.7 & \multirow{4}{*}{15.8884} & \multirow{4}{*}{$<0.01$} \\
\hline Public & $\begin{array}{c}26.7 \\
(24.5-28.9)\end{array}$ & 16.9 & 9.8 & & \\
\hline Both public and private & $\begin{array}{c}9.0 \\
(7.7-10.4)\end{array}$ & 5.5 & 3.4 & & \\
\hline Other insurance & $\begin{array}{c}1.9 \\
(1.3-2.4)\end{array}$ & 1.5 & 0.4 & & \\
\hline
\end{tabular}

*Tests for difference in proportion among the groups were statistically significant $(p<0.05)$. $p$ values were determined with the Pearson design-based $F$ test. 


\section{Multiple Logistic Regression Analysis for CSHCN in General}

Logistic regression analyses were used to examine the relationship between care coordination, family-centered care and the dependent variable (limitation in functional ability) in CSHCN. In addition, the independent associations of number of health conditions, household poverty level, household educational level, and type of health insurance and the dependent variable, limitation in functional ability, were included in this model to limit the effect of identified confounders. Table 14 presents the results of the multivariate analyses, including unadjusted and adjusted odds ratios (OR), 95\% confidence intervals and p-values.

Care coordination was a very significant predictor in both unadjusted and adjusted models $(p<0.001)$. CSHCN that did not receive care coordination had a 53\% increased risk $(\mathrm{OR}=1.53,95 \% \mathrm{CI} 1.21-1.94)$ for a limitation in the ability to perform activities compared to $\mathrm{CSHCN}$ that received care coordination, adjusted for demographic characteristics and covariates that tested significant in bivariate analyses. Other significant predictors of functional limitation were having three $(\mathrm{OR}=2.64,95 \% \mathrm{CI} 1.56$ - 4.47) or four or more conditions $(\mathrm{OR}=8.92,95 \% \mathrm{CI} 5.13-15.50)$, high school graduate educational level $(\mathrm{OR}=1.45,95 \% \mathrm{CI} 1.07-1.95)$, having public insurance $(\mathrm{OR}=1.48$, 95\%CI 1.04 - 2.11) and having both public/private insurance $(\mathrm{OR}=1.56,95 \% \mathrm{CI} 1.05$ 2.30). Age was a statistically significant protective factor $(\mathrm{OR}=0.97,95 \% \mathrm{CI} 0.94$ $0.99)$.

Family-centered care was found to be significant in unadjusted or crude analysis, but turned to be a not significant predictor of limitation in functional ability $(p=0.61)$ after adjusting for care coordination, sociodemographic variables, health insurance 
coverage and type of health insurance. A crosstab analysis of care coordination and family-centered care demonstrated a statistical significant relation between both (Pearson design-based $\mathrm{F}$ test $=263.55, p<0.001$ ). In the logistic regression analysis, familycentered care lost its significance when care coordination was entered into the model. Care coordination maintained its significance in all regression analyses. Family-centered care might be acting as a confounder, and that's why this report includes the results from the combined logistic regression model that includes family-centered care as one of the independent variables along with other covariates.

Table 14

Multivariate Logistic Regression Models Examining the Relationship between Functional Limitation and Care Coordination, Family-Centered Care and Covariates $(n=4,977)$

\begin{tabular}{|c|c|c|c|c|}
\hline Characteristic & $\begin{array}{c}\text { Unadjusted } \\
\text { Odds } \\
\text { Ratio } \\
(95 \% \mathrm{CI}) \\
\end{array}$ & $\begin{array}{c}\text { Unadjusted } \\
\text { p value }\end{array}$ & $\begin{array}{l}\text { Adjusted } \\
\text { Odds } \\
\text { Ratio* } \\
(95 \% \mathrm{CI})\end{array}$ & $\begin{array}{c}\text { Adjusted } \\
\mathrm{p} \text { value }\end{array}$ \\
\hline \multicolumn{5}{|l|}{ Care coordination } \\
\hline Yes & 1.00 & & 1.00 & \\
\hline No & $\begin{array}{c}2.11 \\
(1.70-2.62)\end{array}$ & $<0.001$ & $\begin{array}{c}1.53 \\
(1.21-1.94)\end{array}$ & $<0.001$ \\
\hline \multicolumn{5}{|l|}{ Family-centered care } \\
\hline Yes & 1.00 & & 1.00 & \\
\hline No & $\begin{array}{c}1.57 \\
(1.26-1.95)\end{array}$ & $<0.001$ & $\begin{array}{c}1.07 \\
(0.83-1.37)\end{array}$ & 0.613 \\
\hline Age (numeric) & $\begin{array}{c}1.00 \\
(0.98-1.03)\end{array}$ & 0.958 & $\begin{array}{c}0.97 \\
(0.94-0.99)\end{array}$ & 0.023 \\
\hline \multicolumn{5}{|l|}{ Sex } \\
\hline Female & 1.00 & & 1.00 & \\
\hline Male & $\begin{array}{c}1.08 \\
(0.87-1.34)\end{array}$ & 0.469 & $\begin{array}{c}1.03 \\
(0.82-1.30)\end{array}$ & 0.792 \\
\hline
\end{tabular}




\begin{tabular}{|c|c|c|c|c|}
\hline Characteristic & $\begin{array}{l}\text { Unadjusted } \\
\text { Odds } \\
\text { Ratio } \\
(95 \% \mathrm{CI}) \\
\end{array}$ & $\begin{array}{c}\text { Unadjusted } \\
\text { p value }\end{array}$ & $\begin{array}{l}\text { Adjusted } \\
\text { Odds } \\
\text { Ratio* } \\
(95 \% \mathrm{CI}) \\
\end{array}$ & $\begin{array}{c}\text { Adjusted } \\
\mathrm{p} \text { value }\end{array}$ \\
\hline \multicolumn{5}{|l|}{ Race } \\
\hline White & 1.00 & & 1.00 & \\
\hline Hispanic & $\begin{array}{c}1.17 \\
(0.83-1.64)\end{array}$ & 0.377 & $\begin{array}{c}0.97 \\
(0.66-1.43)\end{array}$ & 0.871 \\
\hline Black & $\begin{array}{c}1.11 \\
(0.81-1.50)\end{array}$ & 0.516 & $\begin{array}{c}0.80 \\
(0.55-1.16)\end{array}$ & 0.241 \\
\hline Multirace & $\begin{array}{c}0.75 \\
(0.44-1.27)\end{array}$ & 0.280 & $\begin{array}{c}0.61 \\
(0.36-1.04)\end{array}$ & 0.067 \\
\hline Other & $\begin{array}{c}0.87 \\
(0.47-1.59)\end{array}$ & 0.644 & $\begin{array}{c}0.77 \\
(0.46-1.31)\end{array}$ & 0.337 \\
\hline \multicolumn{5}{|l|}{ Number of health conditions } \\
\hline None & 1.00 & & 1.00 & \\
\hline One & $\begin{array}{c}0.49 \\
(0.38-0.62)\end{array}$ & $<0.001$ & $\begin{array}{c}1.26 \\
(0.76-2.09)\end{array}$ & 0.375 \\
\hline Two & $\begin{array}{c}0.64 \\
(0.49-0.82)\end{array}$ & $<0.001$ & $\begin{array}{c}1.52 \\
(0.92-2.51)\end{array}$ & 0.106 \\
\hline Three & $\begin{array}{c}1.37 \\
(1.05-1.79)\end{array}$ & 0.018 & $\begin{array}{c}2.64 \\
(1.56-4.47)\end{array}$ & $<0.001$ \\
\hline Four or more conditions & $\begin{array}{c}6.67 \\
(4.94-9.00)\end{array}$ & $<0.001$ & $\begin{array}{c}8.92 \\
(5.13-15.50)\end{array}$ & $<0.001$ \\
\hline \multicolumn{5}{|l|}{ Household poverty level } \\
\hline $200-399 \%$ & $\begin{array}{c}0.70 \\
(0.55-0.90)\end{array}$ & 0.004 & $\begin{array}{c}0.91 \\
(0.68-1.20)\end{array}$ & 0.487 \\
\hline $100-199 \%$ & $\begin{array}{c}1.54 \\
(1.20-1.99)\end{array}$ & 0.001 & $\begin{array}{c}1.06 \\
(0.75-1.49)\end{array}$ & 0.754 \\
\hline$<100 \%$ & $\begin{array}{c}1.65 \\
(1.25-2.17)\end{array}$ & $<0.001$ & $\begin{array}{c}0.97 \\
(0.63-1.49)\end{array}$ & 0.896 \\
\hline \multicolumn{5}{|l|}{ Household educational level } \\
\hline More than high school & 1.00 & & 1.00 & \\
\hline High school graduate & $\begin{array}{c}1.63 \\
(1.26-2.12)\end{array}$ & $<0.001$ & $\begin{array}{c}1.45 \\
(1.07-1.95)\end{array}$ & 0.015 \\
\hline Less than high school & $\begin{array}{c}1.41 \\
(0.89-2.21)\end{array}$ & 0.140 & $\begin{array}{c}0.98 \\
(0.52-1.82)\end{array}$ & 0.938 \\
\hline
\end{tabular}




\begin{tabular}{|c|c|c|c|c|}
\hline Characteristic & $\begin{array}{l}\text { Unadjusted } \\
\text { Odds } \\
\text { Ratio } \\
(95 \% \mathrm{CI}) \\
\end{array}$ & $\begin{array}{l}\text { Unadjusted } \\
\text { p value }\end{array}$ & $\begin{array}{l}\text { Adjusted } \\
\text { Odds } \\
\text { Ratio* } \\
(95 \% \mathrm{CI})\end{array}$ & $\begin{array}{l}\text { Adjusted } \\
\text { p value }\end{array}$ \\
\hline \multicolumn{5}{|l|}{ Health insurance } \\
\hline Yes & 1.00 & & 1.00 & \\
\hline No & $\begin{array}{c}1.07 \\
(0.61-1.87)\end{array}$ & 0.819 & $\begin{array}{c}1.03 \\
(0.57-1.88)\end{array}$ & 0.911 \\
\hline \multicolumn{5}{|l|}{ Type of health insurance } \\
\hline Private & 1.00 & & 1.00 & \\
\hline Public & $\begin{array}{c}1.86 \\
(1.46-2.37)\end{array}$ & $<0.001$ & $\begin{array}{c}1.48 \\
(1.04-2.11)\end{array}$ & 0.032 \\
\hline Both public and private & $\begin{array}{c}1.89 \\
(1.35-2.66)\end{array}$ & $<0.001$ & $\begin{array}{c}1.56 \\
(1.05-2.30)\end{array}$ & 0.026 \\
\hline $\begin{array}{l}\text { Other comprehensive } \\
\text { insurance }\end{array}$ & $\begin{array}{c}0.77 \\
(0.40-1.46)\end{array}$ & 0.419 & $\begin{array}{c}0.90 \\
(0.48-1.69)\end{array}$ & 0.740 \\
\hline
\end{tabular}

*Odds ratios were adjusted simultaneously for family-centered care, age, sex, race, number of health conditions, household poverty and educational level, health insurance and type of health insurance. Results in bold are statistically significant $(p<0.05)$.

\section{Multiple Logistic Regression Analysis for CSHCN with a Specific Health Condition}

Logistic regression analyses were also used to examine the relationship between care coordination, family-centered care and the dependent variable (functional limitation) by stratifying by a health condition, in this case, by children with Attention Deficit Disorder/Attention Deficit Hyperactive Disorder (ADD/ADHD). This was done to compare the results between children with special needs in general and children with a specific health condition and to determine if the variables that were significantly associated with functional limitation in $\mathrm{CSHCN}$ in general are also significant for children who have a specific condition.

There were 1,528 children with ADD/ADHD in the sample, representing approximately $391,906 \mathrm{CSHCN}$ with this health condition in the population. Table 15 presents the percent of CSHCN that had the condition. Approximately, $31.2 \%(95 \% \mathrm{CI}$ 
$29.4 \%-33.9 \%$ ) of CSHCN had ADD/ADHD. Ten percent of these children had a functional limitation.

Table 15

Percent of CSHCN with ADD/ADHD and Functional Limitation $(n=1,528)$

\begin{tabular}{|c|c|c|c|c|c|}
\hline \multirow[t]{2}{*}{ Characteristic } & \multirow[t]{2}{*}{$\begin{array}{l}\mathrm{CSHCN} \text { in } \\
\text { general } \\
\text { Weighted \% } \\
(95 \% \mathrm{CI})\end{array}$} & \multicolumn{2}{|c|}{$\begin{array}{l}\text { Limitation in } \\
\text { Functional } \\
\text { Ability } \\
\text { Weighted \% }\end{array}$} & \multirow[t]{2}{*}{$\begin{array}{c}\text { Pearson } \\
\text { design- } \\
\text { based F test }\end{array}$} & \multirow[t]{2}{*}{$\begin{array}{c}\mathrm{p} \\
\text { value }\end{array}$} \\
\hline & & No & Yes & & \\
\hline \multicolumn{6}{|l|}{ ADD/ADHD* } \\
\hline No & $\begin{array}{c}68.3 \\
(66.1-70.6)\end{array}$ & 52.1 & 16.3 & \multirow[t]{2}{*}{14.26} & \multirow{2}{*}{$\begin{array}{c}\stackrel{<}{0} \\
0.001\end{array}$} \\
\hline Yes & $\begin{array}{c}31.2 \\
(29.4-33.9)\end{array}$ & 21.4 & 10.3 & & \\
\hline
\end{tabular}

*Tests for difference in proportion among the groups were statistically significant $(p<$ 0.05). $\mathrm{p}$ values were determined with the Pearson design-based F test.

Table 16 presents the results of the multivariate analyses, including unadjusted and adjusted odds ratios (OR), 95\% confidence intervals and $\mathrm{p}$ values. Care coordination was a significant predictor in both unadjusted and adjusted models $(p=0.01)$. CSHCN that did not receive care coordination had $65 \%$ increased risk for a limitation in the ability to perform activities $(\mathrm{OR}=1.65,95 \% \mathrm{CI} 1.11-2.46)$ compared to $\mathrm{CSHCN}$ that received care coordination, adjusted for demographic characteristics and covariates. Some of the variables that were significant in the adjusted model for CSHCN in general were also significant for $\mathrm{CSHCN}$ with $\mathrm{ADD} / \mathrm{ADHD}$. These variables were number of health conditions and high school graduate household educational level $(p<0.05)$. 
Table 16

Multivariate Logistic Regression of the Relationship between Functional Limitation, Care Coordination, Family-Centered Care and Covariates in CSHCN with ADD/ADHD $(n=1,528)$

\begin{tabular}{|c|c|c|c|c|}
\hline Characteristic & $\begin{array}{c}\text { Unadjusted } \\
\text { Odds } \\
\text { Ratio } \\
(95 \% \mathrm{CI})\end{array}$ & $\begin{array}{l}\text { Unadjusted } \\
\text { p value }\end{array}$ & $\begin{array}{l}\text { Adjusted } \\
\text { Odds } \\
\text { Ratio* } \\
(95 \% \mathrm{CI})\end{array}$ & $\begin{array}{l}\text { Adjusted } \\
\mathrm{p} \text { value }\end{array}$ \\
\hline \multicolumn{5}{|l|}{ Care coordination } \\
\hline Yes & 1.00 & & 1.00 & \\
\hline No & $\begin{array}{c}2.05 \\
(1.43-2.93)\end{array}$ & $<0.001$ & $\begin{array}{c}1.65 \\
(1.11-2.46)\end{array}$ & 0.014 \\
\hline \multicolumn{5}{|l|}{ Family-centered care } \\
\hline $\begin{array}{l}\text { Yes } \\
\text { No }\end{array}$ & $\begin{array}{c}1.00 \\
1.17 \\
(0.81-1.68)\end{array}$ & 0.409 & $\begin{array}{c}1.00 \\
0.79 \\
(0.52-1.19)\end{array}$ & 0.258 \\
\hline Age (numeric) & $\begin{array}{c}1.03 \\
(0.97-1.08)\end{array}$ & 0.310 & $\begin{array}{c}1.03 \\
(0.98-1.08)\end{array}$ & 0.295 \\
\hline \multicolumn{5}{|l|}{ Sex } \\
\hline Female & 1.00 & & 1.00 & \\
\hline Male & $\begin{array}{c}0.90 \\
(0.62-1.31)\end{array}$ & 0.574 & $\begin{array}{c}0.95 \\
(0.63-1.42)\end{array}$ & 0.795 \\
\hline \multicolumn{5}{|l|}{ Race } \\
\hline White & 1.00 & & 1.00 & 1.00 \\
\hline Hispanic & $\begin{array}{c}1.50 \\
(0.82-2.76)\end{array}$ & 0.189 & $\begin{array}{c}1.19 \\
(0.59-2.39)\end{array}$ & 0.619 \\
\hline Black & $\begin{array}{c}0.80 \\
(0.49-1.31)\end{array}$ & 0.380 & $\begin{array}{c}0.76 \\
(0.43-1.34)\end{array}$ & 0.346 \\
\hline Multirace & $\begin{array}{c}1.25 \\
(0.57-2.75)\end{array}$ & 0.579 & $\begin{array}{c}1.24 \\
(0.49-3.15)\end{array}$ & 0.655 \\
\hline Other & $\begin{array}{c}1.69 \\
(0.64-4.47)\end{array}$ & 0.289 & $\begin{array}{c}1.60 \\
(0.72-3.53)\end{array}$ & 0.248 \\
\hline \multicolumn{5}{|c|}{ Number of health conditions } \\
\hline None & 1.00 & & 1.00 & 1.00 \\
\hline One & $\begin{array}{c}0.23 \\
(0.14-0.39)\end{array}$ & $<0.001$ & $\begin{array}{c}0.09 \\
(0.06-0.18)\end{array}$ & $<0.001$ \\
\hline Two & $\begin{array}{c}0.47 \\
(0.32-0.71)\end{array}$ & $<0.001$ & $\begin{array}{c}0.19 \\
(0.12-0.31)\end{array}$ & $<0.001$ \\
\hline Three & $\begin{array}{c}0.82 \\
(0.54-1.24)\end{array}$ & 0.352 & $\begin{array}{r}0.27 \\
(0.17-0.44) \\
\quad \text { (tab }\end{array}$ & $\begin{array}{l}<\mathbf{0 . 0 0 1} \\
\text { continues }\end{array}$ \\
\hline
\end{tabular}




\begin{tabular}{|c|c|c|c|c|}
\hline Characteristic & $\begin{array}{c}\text { Unadjusted } \\
\text { Odds } \\
\text { Ratio } \\
(95 \% \mathrm{CI}) \\
\end{array}$ & $\begin{array}{l}\text { Unadjusted } \\
\text { p value }\end{array}$ & $\begin{array}{l}\text { Adjusted } \\
\text { Odds } \\
\text { Ratio* } \\
(95 \% \mathrm{CI}) \\
\end{array}$ & $\begin{array}{l}\text { Adjusted } \\
\text { p value }\end{array}$ \\
\hline Four or more conditions & $\begin{array}{c}5.85 \\
(3.95-8.67)\end{array}$ & $<0.001$ & omitted $* * *$ & \\
\hline \multicolumn{5}{|l|}{ Household poverty level } \\
\hline $400 \%$ or higher & 1.00 & & 1.00 & 1.00 \\
\hline $200-399 \%$ & $\begin{array}{c}0.69 \\
(0.42-1.12)\end{array}$ & 0.132 & $\begin{array}{c}0.93 \\
(0.54-1.61)\end{array}$ & 0.791 \\
\hline $100-199 \%$ & $\begin{array}{c}1.47 \\
(0.97-2.23)\end{array}$ & 0.068 & $\begin{array}{c}1.32 \\
(0.69-2.52)\end{array}$ & 0.408 \\
\hline$<100 \%$ & $\begin{array}{c}1.63 \\
(1.07-2.48)\end{array}$ & 0.022 & $\begin{array}{c}1.37 \\
(0.66-2.82)\end{array}$ & 0.400 \\
\hline \multicolumn{5}{|l|}{ Household educational level } \\
\hline More than high school & 1.00 & & 1.00 & 1.00 \\
\hline High school graduate & $\begin{array}{c}1.66 \\
(1.09-2.50)\end{array}$ & 0.016 & $\begin{array}{c}1.71 \\
(1.07-2.73)\end{array}$ & 0.025 \\
\hline Less than high school & $\begin{array}{c}1.06 \\
(0.57-1.99)\end{array}$ & 0.848 & $\begin{array}{c}0.76 \\
(0.36-1.60)\end{array}$ & 0.466 \\
\hline \multicolumn{5}{|l|}{ Health insurance } \\
\hline Yes & 1.00 & & 1.00 & 1.00 \\
\hline No & $\begin{array}{c}1.06 \\
(0.37-3.07)\end{array}$ & 0.91 & $\begin{array}{c}0.71 \\
(0.24-2.14)\end{array}$ & 0.546 \\
\hline \multicolumn{5}{|l|}{ Type of health insurance } \\
\hline Private & 1.00 & & 1.00 & 1.00 \\
\hline Public & $\begin{array}{c}1.80 \\
(1.23-2.63)\end{array}$ & 0.002 & $\begin{array}{c}1.15 \\
(0.65-2.03)\end{array}$ & 0.630 \\
\hline Both public and private & $\begin{array}{c}1.22 \\
(0.70-2.11)\end{array}$ & 0.482 & $\begin{array}{c}0.89 \\
(0.47-1.69)\end{array}$ & 0.716 \\
\hline $\begin{array}{l}\text { Other comprehensive } \\
\text { insurance }\end{array}$ & $\begin{array}{c}0.85 \\
(0.26-2.80)\end{array}$ & 0.79 & $\begin{array}{c}0.64 \\
(0.21-1.93)\end{array}$ & 0.429 \\
\hline
\end{tabular}

* Odds ratios are adjusted simultaneously for family-centered care, age, sex, race, number of health conditions, household poverty and educational level, health insurance and type of health insurance.

$* *$ Results in bold are statistically significant $(p<0.05)$.

$* * *$ Results omitted because of collinearity. 


\section{Summary of the Results}

The results of this study rejected the first null hypothesis demonstrating that care coordination is associated with the ability of CSHCN to perform activities that most children of the same age can perform generally, controlling for age, gender, number of health conditions, household poverty level, household educational level, health insurance, and type of health insurance. These results are consistent with the literature that suggests that care coordination may play a role in the health outcomes for CSHCN. This finding also supports the socioecological multilevel model that was used as a framework for this study.

The analysis failed to reject the second null hypothesis that stated that familycentered care is not associated with the ability of CSHCN to perform activities that most children of the same age can perform generally, controlling for care coordination, age, gender, number of health conditions, household poverty level, household educational level, health insurance, and type of health insurance.

Analyses were also made for $\mathrm{CSHCN}$ with $\mathrm{ADD} / \mathrm{ADHD}$. Results were similar to those found for $\mathrm{CSHCN}$ in general. Lack of care coordination was a significant predictor of functional limitation in children with ADD/ADHD, after adjusting for covariates ( $p=$ 0.01). The risk for having a limitation in functional ability due to lack of care coordination was higher for $\mathrm{CSHCN}$ with $\mathrm{ADD} / \mathrm{ADHD}(\mathrm{OR}=1.65,95 \% \mathrm{CI} 1.11$ - 2.46) compared to $\mathrm{CSHCN}$ in general $(\mathrm{OR}=1.53,95 \% \mathrm{CI} 1.21-1.94)$, adjusting for covariates. Having one, two or three conditions was also significant, but as a protective factor $(\mathrm{OR}<$ 1.00 ), contrary to what was found for CSHCN in general in which having three or four or more conditions increased the risk for having a functional limitation. The risk for having 
a limitation in functional ability was higher for $\mathrm{CSHCN}$ with $\mathrm{ADD} / \mathrm{ADHD}$ that were in a household where parents had a high school educational level $(\mathrm{OR}=1.71,95 \% \mathrm{CI} 1.07$ 2.73) compared to $\mathrm{CSHCN}$ in general $(\mathrm{OR}=1.45,95 \% \mathrm{CI} 1.07-1.95)$, adjusting for covariates. Family-centered care was not found to be a significant predictor of functional ability in CSHCN with ADD/ADHD.

In conclusion, findings from this study are consistent with the socioecological multilevel model and literature review for the association between care coordination and functionality of CSHCN. This study also confirms a lack of association of familycentered care and functionality of CSHCN. Chapter 5 discusses these results, their implications, and recommendations for future action and research. 
Chapter 5: Discussion, Conclusion and Implications for Social Change

\section{Introduction}

The purpose of this study was to determine if there is an association between care coordination, family-centered care and functional ability in CSHCN. CSHCN often have complex health conditions, limitations, and needs that require diverse health and community services in order to improve health, functionality, and quality of children's lives (Eiser \& Moore, 2001). Most studies on care coordination and family-centered care focus on met and unmet health care needs, and only few address health outcomes. This study was developed to evaluate two hypotheses, if care coordination was associated with functional ability in $\mathrm{CSHCN}$ and if family-centered care was associated with functional ability in CSHCN, adjusting for covariates.

The design of this study was a secondary analysis of data from the 2005-2006 National Survey of CSHCN. The study was guided by an adapted socioecological multilevel conceptual framework that considered the relation of child, family, community and society characteristics with functional ability in CSHCN. Functional ability limitation was the dependent variable. Care coordination and family-centered care were the independent variables. Covariates included age, gender, race, number of conditions, family poverty level, household educational level, health insurance, and type of health insurance. Univariate, bivariate, and multivariate models were used to analyze data.

It is important to mention that children identified with special health care needs and functional limitation in the survey may have substantial variation in the degree of functional ability limitation. 


\section{Care Coordination}

The results of this study indicate that care coordination may play an important role in the functional ability of CSHCN. In this study, not receiving care coordination was significantly associated with a limitation in functional ability in CSHCN before (OR $=2.11,1.70-2.62, p<0.01)$ and after controlling for sociodemographic and other covariates $(\mathrm{OR}=1.53,95 \% \mathrm{CI} 1.21-1.9, p<0.01)$. This means that $\mathrm{CSHCN}$ that did not receive care coordination were at 1.53 times the risk or $53 \%$ increased risk for a limitation in functional ability compared to $\mathrm{CSHCN}$ that received care coordination.

Findings in this study are consistent with what has been previously found in terms of health outcomes. According to the literature, care coordination may play an important role in identifying, finding and accessing services and community resources for CSHCN (AAP, 2005). For example, Palfrey et al. (2004) studied the impact of a care coordination intervention on children's hospitalizations. Results of the study showed a statistically significant decrease in children's hospitalizations ( $58 \%$ baseline vs. $43.2 \%$ after intervention; $p<0.01$ ) after receiving care coordination. Families of children with severe conditions were most likely to easy use care services and to be more satisfied with services when they obtained the help of the pediatric nurse practitioner. Antonelli et al. (2008), in a study of pediatric practices, also found that care coordination help reduce children's doctor office visits in 58\%, emergency department visits in $26 \%$, subspecialist visits in $10 \%$, hospitalizations in $4 \%$, and use of therapies in $1 \%$. Care coordination also promoted family's satisfaction with health services (Palfrey et al., 2004).

Other significant variables that were found to be associated with functional ability in this study were age $(\mathrm{OR}=0.97,95 \% \mathrm{CI} 0.940 .99, p=0.02)$; having three health 
conditions $(\mathrm{OR}=2.64,95 \% \mathrm{CI} 1.56-4.47, p<0.01)$; having four or more conditions $(\mathrm{OR}$ $=8.92,95 \%$ CI $5.13-15.50, p<0.01)$; living in a high school graduate household educational level $(\mathrm{OR}=1.42,95 \% 1.07-1.95, p=0.01)$; having public insurance $(\mathrm{OR}=$ $1.48,95 \% \mathrm{CI} 1.04-2.11, p=0.03)$; and, having both public and private health insurance $(\mathrm{OR}=1.56,95 \% \mathrm{CI} 1.05-2.30, p=0.02)$. Some of these results are consistent with what has been found in literature. For example, Newacheck et al. (2000) found that CSHCN that live in low income households and lack health insurance are at increased risk for unmet needs.

The level of education is also a factor that has been identified as an important factor in the health care process. Benedict (2006), who studied if family resources predict the use of services by school-age children with functional limitations, found that children that lived in households where the parents had a high school education level were at increased odds for therapeutic $(\mathrm{OR}=1.48,95 \% \mathrm{CI} 1.09-2.00)$ and supportive service use $(\mathrm{OR}=1.92,95 \% \mathrm{CI} 1.17$ - 3.16) compared to children that lived in households where the parents had less than high school education. Children with public insurance were also at increased odds for therapeutic $(\mathrm{OR}=2.19,95 \% \mathrm{CI} 1.57-3.06)$ and supportive service use $(\mathrm{OR}=3.30,95 \% \mathrm{CI} 1.70-6.41)$ compared to children with no insurance. It has been argued that families with greater education tend to seek more information and be more knowledgeable about health conditions, needs and service availability, especially if they have children with functional limitations (Benedict, 2006). These findings are important because CSHCN need services in order to maintain or improve their health and functionality and to maximize their skills and social integration. 
This study found that the type of health insurance is a factor associated with functional limitation, especially in children with public/private insurance or public insurance alone. The type of health insurance can influence the accessibility of children to needed health services. For example, in a study by Kogan et al. (2005), it was found that children who had a limitation in their daily activities were most likely to be underinsured $(\mathrm{OR}=1.18,95 \% \mathrm{CI} 1.03-1.35)$, compared to children without a limitation. Underinsured children were those that had health insurance that do not cover for all services needed. In another study, it was found that CSHCN with adequate health insurance were 2.3 times more likely to receive care coordination services compared to children with inadequate health insurance (Tippy et al., 2005).

Data in this study were also analyzed for children with a specific condition, in this case, $\mathrm{CSHCN}$ with ADD/ADHD. According to literature, the prevalence of ADD ranges between $4-12 \%$ of children in the US (Brown et al., 2001). The disorder is of public health concern due to several reasons that include: a) its potential consequences on health and functioning, $b$ ) the increasing number of referrals for evaluation and treatment, and c) its lifetime persistence (NIH, 1998). Additionally, the condition co-occurs with other emotional, learning and conduct problems (Brown, Freeman, Perrin, Stein, Amler, Feldman, Pierce, \& Wolraich, 2001). In this study, condition-specific analyses revealed that care coordination was also a significant predictor of functional ability in CSHCN with ADD/ADHD. Children with ADD/ADHD that did not receive care coordination were at 1.65 times the risk for a limitation in functional ability $(95 \%$ CI $1.11-2.46)$ compared to children that received care coordination, adjusting for sociodemographic and 
other covariates. This result compared to the results for CSHCN in general, where care coordination also plays an important role in children's functional ability.

It has been found that a good collaboration between the pediatrician and the psychiatrist play an important role in the quality of care for children with ADD/ADHD (Ross, Chan, Harris, Goldman, \& Rappaport, 2011). An effective collaboration between providers is part of care coordination, which demonstrates the importance of this process in the care for CSHCN. Similar to the results for CSHCN in general, living in a high school graduate household educational level was a significant predictor of functional ability before $(\mathrm{OR}=1.66,95 \% \mathrm{CI} 1.09-2.50, p=0.01)$ and after $(\mathrm{OR}=1.71,95 \% \mathrm{CI}$ $1.07-2.73, p=0.02$ ) controlling for sociodemographic and health insurance variables. As discussed before, household educational level is a predictor of service use and can impact the health and functionality of CSHCN.

\section{Family-Centered Care}

Family-centered care is another element that has been proposed to play an important role in the adequate care for $\mathrm{CSHCN}$. There is a gap in literature regarding the association of family-centered care and functionality in CSHCN. In this study, familycentered care was found to be a significant predictor in crude or unadjusted multivariate analysis $(p<0.01)$, but was not found to be significantly associated with functional ability limitation in CSHCN when other variables are included in the model, including care coordination and other sociodemographic and health insurance covariates $(p=0.61)$. This contrasts with what has been found in research studies on other health outcomes, such as, skills development and psychological health. One of the reviewed studies found that children with cerebral palsy improved their skills and development after participating 
in a family-centered health care program compared to children that participated in a standard program (Law et al., 1998). Other studies found that family-centered care promoted healthy psychosocial development in children with chronic conditions that participated in a service program that focused on the family compared to children that received services from a standard health care program (King et al., 2004). It is important to mention that previous studies on family-centered care measured outcomes from interventions or from the participation in programs. Results may differ from this study that analyzed secondary data from a national parental survey.

Although family-centered care was not found to be associated with functional ability in CSHCN, it is important in other health care aspects, such as, increased family's satisfaction with services, diminished number of missed school days, and lower unmet health needs and unmet family needs. Family-centered care helps increase satisfaction with health services (Ngui \& Flores, 2006) and have been found to diminish the risk for school absences, unmet health needs and unmet family needs (Denboba et al, 2006). Additional research in needed to further explore the relationship of family-centered care with children's health care outcomes.

\section{Summary}

In this study it was found that care coordination is significantly associated with functional ability in CSHCN after controlling for sociodemographic and covariates. CSHCN that did not receive care coordination were at 1.53 times the risk for a limitation in functional ability (95\%CI $1.21-1.9)$ compared to CSHCN that received care coordination. This result is consistent with previous studies on the effect of care coordination on health outcomes (Palfrey et al., 2004). The study also found that other 
statistically significant variables associated with functional ability were age, number of health conditions, household poverty level and having public insurance. Previous studies have found that parental education and health insurance are important predictors of service use (Benedict, 2006; Kogan et al., 2005; Newacheck et al., 2000; Tippy et al., 2005).

Care coordination was also a statistically significant predictor of functional ability in $\mathrm{CSHCN}$ with $\mathrm{ADD} / \mathrm{ADHD}$. Children with $\mathrm{ADD} / \mathrm{ADHD}$ that did not receive care coordination were at 1.65 times the risk for a limitation in functional ability (95\%CI 1.11 - 2.46) compared to children that received care coordination, adjusting for covariates. This reinforces the conclusion that care coordination is important and necessary in the care for $\mathrm{CSHCN}$ in general and by condition, in this case, CSHCN with ADD/ADHD.

Family-centered care was not found to be associated with a limitation in functional ability in $\operatorname{CSHCN}(p=0.61)$. This contrasts with what has been previously found in literature. This element has been found to increase family's satisfaction and improved health outcomes in CSHCN that participated in programs with family-centered focus (King et al., 2004; Law et al., 1998).

Results of this study are consistent with the multilevel socio-ecological model that explains the effect of individual, family, community and societal factors on the functional ability of CSHCN. For example, age and number of health conditions were associated with functional ability at the individual or child-level. Household educational level was also a significant factor on functional ability at the family-level. Type of health insurance at the community-level was also a significant factor associated with functional ability in 
CSHCN. Care coordination at the society-level was one of the main independent variables that resulted to be statistically associated with functional ability in CSHCN.

\section{Implications for Social Change}

This study has various implications for social change. This study contributed to positive social change by providing evidence that may serve to improve the health care outcomes for this population in the US. The current health care system for this population has been described as fragmented and families have difficulties in obtaining the necessary health and related services for their children (Roberts, Behl, \& Akers, 2004). Additionally, CSHCN use a high amount of child health care dollars compared to typical children (Boyle, Decoufle, and Yeargin-Allsopp 1994; Newacheck et al. 1994, 1998b; Ireys et al. 1997; Ray et al. 2000).

Evidence obtained from this study that care coordination is associated with functional ability can be used by health care providers, government agencies, policy makers and other stakeholders in health care decision making, in identifying ways to improve the current health care system and in developing interventions or programs for CSHCN and their families. Other factors that can also be considered in promoting children's better health outcomes are the level of education of parents and having public health insurance, both of which can affect access to services and therefore children's functionality. This study may also promote further research to determine how these factors affect services and to identify the specific care coordination elements that can be improved for a better health care system for these children and their families. 


\section{Recommendations for Action}

This study provides evidence that care coordination plays an essential role in the functionality of CSHCN. These children often have complex health conditions that compromise their health and quality of life. They need a variety of health and related services in order to improve their health outcomes. It is necessary to increase awareness among health care providers, public health officials and policy makers on the importance of providing care coordination to $\mathrm{CSHCN}$ as part of the health care process. Several barriers have been previously identified by pediatricians in providing care coordination, including coverage by health insurance companies and payment for their time and effort in providing this service to their patients, among others (AAP, 2005; Bhushan-Gupta, O'Connor and Quezada-Gomez, 2004). These barriers should be resolved in order to promote health care professionals to provide care coordination in their practices. Care coordination can contribute to identify and connect with the services that CSHCN and their families need in an organized manner. This would improve the current health care system and at the same time provide health benefits to CSHCN and their families.

\section{Limitations of the Study}

This study is based on the secondary data analysis of a national survey. Responses were obtained from families of CSHCN, which are considered self-reported data. This type of data cannot be corroborated with other data sources, such as medical records or service claims. Data obtained from surveys are also subjected to recall and reporting bias. Recall bias occurs when respondents have difficulties remembering remote service encounters compared to recent events. Participants may also have provided involuntary erroneous information or refused to answer some questions which 
may cause reporting and information biases affecting therefore the quality of data that are obtained. This study is observational in nature, which impedes to establish causality or directionality in the relation between independent and dependent variables. It is important to note that the causal flow was assumed to go from care coordination to functional ability but if this assumption was incorrect, then findings may be misleading. Also, cases with missing values were deleted from analyses. These limitations can probably result in an underestimation of association measures.

Despite the limitations, the main advantage of this study is the use of data from a nationally representative sample, and findings can be generalized to the US population. Another advantage is the use of expert-developed questions that were validated during a previous implementation of the survey at the national level.

It is also important to mention that the results from analyses of $\mathrm{ADD} / \mathrm{ADHD}$ children were slightly different from the findings obtained for CSHCN in general. Significant predictors of functional ability in CSHCN with ADD/ADHD were care coordination, number of health conditions and household educational level. Age and type of health insurance were not significant for CSHCN with ADD/ADHD. There were also differences in the magnitude of association measures. For example, the risk for a limitation in functional ability for children without care coordination was higher for CSHCN with ADD/ADHD than for the general CSHCN population. Additionally, findings specific for CSHCN with $\mathrm{ADD} / \mathrm{ADHD}$ may not apply to children with other health conditions. 


\section{Implications for Future Research}

This study provided information regarding the association of care coordination and functionality in CSHCN. This is consistent with previous studies that propose that care coordination and family-centered care are two essential elements in the health care for CSHCN. Most of these studies use secondary data from representative national CSHCN studies. Only few studies measure the impact of care coordination on specific health outcomes. It would be useful to design intervention studies to determine the effect of care coordination on general and specific functional areas by comparing health outcomes in CSHCN that participate in a care coordination program versus CSHCN that participate in a standard program. It would also be of benefit to develop follow-up studies to establish causality or directionality in the relationship between care coordination and functional ability. These studies can also be developed to compare results in children with different health conditions. These additional studies can provide valuable information to expand knowledge in this area and to develop policies and programs to improve the health care and health outcomes in CSHCN and their families.

\section{Conclusion}

A goal for public health and medicine is to maintain and improve health, life expectancy and quality of life by effectively assigning resources to reduce disease and health disparities in the population (Michaud, Murray \& Bloom, 2001). This study found that $\mathrm{CSHCN}$ that do not receive care coordination are at increased risk for a limitation in functional ability compared to $\mathrm{CSHCN}$ that receive care coordination. This was also found for $\mathrm{CSHCN}$ with $\mathrm{ADD} / \mathrm{ADHD}$. This indicates that care coordination may play an important role in predicting the functional ability of CSHCN. Additional 
research is necessary to compare the effect of care coordination on specific functional areas and/or other health outcomes in CSHCN in general and by specific health conditions.

This study has many implications for social change that include providing important information that can be used by public health officials, health care providers and policy makers in developing policies to assure that care coordination is provided to CSHCN and their families. Care coordination is recommended by the American Academy of Pediatrics (AAP, 2005) to enhance the linkage of patients and their families with needed health and related services in an organized manner. Primary care providers have a central role in care coordination. Barriers that have been identified in previous research need to be addressed in order to promote the provision of care coordination by primary care professionals, including pediatricians. The Institute of Medicine (2001) considers that care coordination can play an essential role in decreasing the difference between the current health system and the system that should exists to provide effective and efficient services to CSHCN and their families. 


\section{References}

American Academy of Pediatrics, Committee on Children with Disabilities. (1999). Care coordination: integrating health and related systems of care for children with special health care needs. Pediatrics, 104(4), 978-981.

American Academy of Pediatrics, Medical Home Initiatives for Children with Special Health Care needs Project Advisory Committee. (2002). The medical home. Pediatrics, 110, 184-186.

American Academy of Pediatrics, Committee on Hospital Care. (2003). Family-centered care and the pediatrician's role. Pediatrics, 112, 691-697.

American Academy of Pediatrics, Council on Children with Disabilities. (2005). Care coordination in the medical home: integrating health and related systems of care for CSHCN. Pediatrics, 116(5), 1238-1244.

Andersen, R.M. (1995). Revisiting the behavioral model and access to medical care: does it matter? Journal of Health and Social Behavior, 36, 1-10.

Antonelli, R.C., Stille, \& C.J., Antonelli, D.M. (2008). Care coordination for children and youth with special Health care needs: a descriptive, multisite study of activities, personnel costs, and outcomes. Pediatrics, 122, e209e216.

Baruffi, G., Miyashiro, L, Prince, C.B, \& Heu, P. (2005). Factors associated with ease of using community-based systems of care for CSHCN in Hawaii. Maternal and Child Health Journal, 9S (2), S99-S108. 
Benedict, R.E. (2006). Disparities in use and unmet need for therapeutic and supportive services among school-age children with functional limitations: a comparison across settings. Health Research and Educational Trust, 41(1), 103-124.

Bethell, C. (2000). Quality Information for People with Special Health Care Needs. Quality Interagency Coordination Task Force, Workgroup on Consumer Health Information. Retrieved from http://www.quic.gov/consumer/conference/bethell1.htm

Bhushan-Gupta, V., O’Connor, K.G, \& Quezada-Gomez, C. (2004). Care coordination services in pediatric practices. Pediatrics, 113(5), 1517-1521.

Bickenbach, J. E. (2001). Disability human rights, law, and policy. In G. L. Albrecht, K. D. Seelman, \& M. Bury (Eds). Handbook of disability studies. Thousand Oaks, CA: Sage Publications, Inc.

Blumberg, S.J., Osborn, L., \& Luke, J., et al. (2004). Estimating the prevalence of uninsured children: An evaluation of data from the National Survey of Children with Special Health Care Needs, 2001. National Center for Health Statistics. Vital Health Statistics, 2(136), 2-46.

Boyle, C.A., Decoufle, P., \& Yeargin-Allsopp, M. (1994). Prevalence and health impact of developmental disabilities in US children. Pediatrics, 93, 339-403.

Brown, R.T., Freeman, W.S. Perrin, J.M., Stein, M.T., Amler, R.W., Feldman, H.M., Pierce, K., Wolraich, M.L. (2001). Prevalence and Assessment of AttentionDeficit/Hyperactivity Disorder in Primary Care Settings. Pediatrics 107(3), p. e43. Retrieved January 21, 2011 from the PEDIATRICS Journal database. 
Centers for Disease Control and Prevention (2005). 2005-2006 National Survey of Children with Special Health Care Needs Questionnaire. Retrieved from http://www.cdc.gov/nchs/data/slaits/NSCSHCNIIEnglishQuest.pdf

Centers for Disease Control and Prevention. (2006). Questionnaire of the 2005 - 06 National Survey of Children with Special Health Care Needs. Retrieved from http://www.cdc.gov/nchs/data/slaits/NSCSHCNIIEnglishQuest.pdf

Centers for Disease Control and Prevention. (2008). Design and Operation of the National Survey of Children with Special Health Care Needs, 2005-2006. Retrieved from http://www.cdc.gov/nchs/data/series/sr_01/sr01_045.pdf Centers for Disease Control and Prevention. (2009). National survey of children with special health care needs 2005-2006. Retrieved from http://www.cdc.gov/nchs/slaits/cshcn.htm

Child and Adolescent Health Measurement Initiative (CAHMI). 2005-2006 National Survey of Children with Special Health Care Needs Indicator Data Set, Data Resource Center for Child and Adolescent Health, www.childhealthdata.org. Child and Adolescent Health Measurement Initiative (CAHMI) (2008). 2005-2006 National Survey of Children with Special Health Care Needs SPSS Codebook. Retrieved from http://www.cshcndata.org/ViewDocument.aspx?item $=260$

Cooley, W.C, \& McAllister, J.W. (2004). Building medical homes: improvement strategies in primary care for children with special health care needs. Pediatrics, 113, 1499 - 1506.

Data Resource Center. (2005). National Survey of CSHCN: Fast Facts about the Survey. Retrieved from http://www.cshondata.org/ViewDocument.aspx?item=188 
Davidoff, A.J. (2004). Insurance for Children With Special Health Care Needs: patterns of coverage and burden on families to provide adequate insurance. Pediatrics, 114(2), 394-403.

Dean, A.G., Sullivan, K.M., \& Soe, M.M. (2009) OpenEpi: Open Source Epidemiologic Statistics for Public Health, Version 2.3. Retrieved July 6, 2010, from http://www.openepi.com/MENU/OpenEpiMenu.htm

Denboba, D., McPherson, M.G., Kenney, M.K., Strickland, B., \& Newacheck, P.W. (2006). Achieving family and provider partnerships for children with special health care needs. Pediatrics, 118, 1607-1615.

Department of Health and Human Services. (2004). The National Survey of Children with Special Health Care Needs Chartbook 2001. Retrieved from http://mchb.hrsa.gov/chscn/

Department of Health and Human Services. (2008). The National Survey of Children with Special Health Care Needs Chartbook 2005-2006. Retrieved from http://mchb.hrsa.gov/cshcn05/

Drum, C. E. (2009). Models and approaches to disability. In C.E. Drum, G.L. Krahn \& H. Bersani (Eds.), Disability and Public Health. (pp 27-44). Washington, DC: American Public Health Association.

Eiser, C., \& Moore, R. (2001). The measurement of quality of life in children: past and future perspectives. Journal of Developmental and Behavioral Pediatrics, 22, 4856. 
Erickson-Warfield, M., \& Gulley, S. (2006). Unmet need and problems accessing specialty medical and related services among children with special health care needs. Maternal and Child Health Journal, 10(2), 201-216.

Fisher-Owens, S.A., Gansky, S.A., Platt, L.J., Weintraub, J.A., \& Mah-J. (2007). Influences on children's oral health: A conceptual model. Pediatrics, 120, e510e520.

Homer, C. Klatka, K., Romm, D., Kuhlthau, K., Bloom, S., Newacheck, P., Van Cleave, J. \& Perrin, J.M. (2008). A review of the evidence for the medical home for Children With Special Health Care Needs. Pediatrics, 122, e922 - e937.

Hough, J.F. (2000). Estimating the health care utilization costs associated with persons with disabilities: data from the Medical Expenditure Panel Survey. Poster presentation, 2000, Annual Meeting of the Association of Health Services Research, Los Angeles, CA.

Institute of Medicine, Committee on Quality Health Care in America. (2001).

Crossing the quality chasm: a new health system for the 21st century. Washington, DC: The National Academies Press.

Institute of Medicine. (2003). The future of the public's health in the $21^{\text {st }}$ century. Washington, DC: National Academy Press.

Katz, S., \& Akpom, C.A. (1976). A measure of primary sociobiological functions. International Journal of Health Services, 6, 493-507.

King, S., Teplicky, R., King, G., \& Rosenbaum, P. (2004). Family-centered service for children with cerebral palsy and their families: A review of the literature. Seminars in Pediatric Neurology, 11(1), 78-86. 
Kogan, M.D., Newacheck, P.W., Honberg, L. \& Strickland, B. (2005). Association between underinsurance and access to care among children with special health care needs in the United States. Pediatrics, 116, 1162-1169.

Law, M., Darrah, J. \& Pollock, N., King, G., Rosenbaum, P., Russell, D., Palisano, R., Harris, S., Armstron, R., \& Watt, J. (1998). Family-centered functional therapy for children with cerebral palsy: An emerging practice model. Physical and Occupational Therapy Pediatrics, 18(1), 83-102.

Lawton, M.P., \& Brody, E.M. (1969). Assessment of older people: self-maintaining and instrumental activities of daily living. Gerontologist, 9, 179-186.

Leigh, W. \& Wheatley, A. (2009). Trends in child health 1997-2006: assessing racial/ethnic disparities in activity limitation. Joint Center for Political and Economic Studies, Washington D.C.

Lepkowski, J. M. (1988). Telephone sampling methods in the United States. In R. M. Groves (Ed.), Telephone Survey Methodology. New York: Wiley. pp. 73-98.

Lollar, D.J., \& Crews, J.E. (2003). Redefining the role of public health in disability. Annual Review Public Health, 24, 195-208.

Mayer, M., Skinner, A., \& Slifkin, R. (2004). Unmet need for routine and specialty care: data from the national survey of children with special health care needs. Pediatrics, 113(2), 109-115.

McAllister, J.W., Presler, E., \& Cooley, C. (2007). Practice-based care coordination: a medical home essential. Pediatrics, 120(3), e723-e733. 
McPherson, M., Arango, P., Fox, H., Lauver, C., McManus, M., Newacheck, P.W., Perrin, J.M., Shonkoff, J.P., \& Strickland, B. (1998). A new definition of Children with Special Health Care Needs. Pediatrics, 102, 137-140.

McPherson, M., Weissman, G., Strickland, B.B., van Dyck, P.C., Blumberg, S.J., \& Newacheck, P.W. (2004). Implementing community-based systems of services for children and youth with special health care needs: How well are we doing? Pediatrics, 113, 1538-1544.

Mitchell, J. M. \& Gaskin, D. J. (2004). Do children receiving Supplemental Security Income who are enrolled in Medicaid fare better under a fee-for service or comprehensive capitation model? Pediatrics, 114, 196-204.

National Committee on Vital and Health Statistics. (2002). Shaping a health statistics vision for the $21^{\text {st }}$ century. Retrieved from http://www.ncvhs.hhs.gov/hsvision/21st\%20final\%20report.pdf

National Institute of Health. (n.d.). Secondary analysis of a large survey database Avoiding the pitfalls. Retrieved from http://painconsortium.nih.gov/symptomresearch/chapter_20/sec3/cabs3pg1.htm National Institutes of Health. (1998). Diagnosis and Treatment of AttentionDeficit/Hyperactivity Disorder. NIH Consensus Statement 16(2). Washington, DC: US Government Printing Office. Retrieved January 21, 2011 from http://consensus.nih.gov/1998/1998AttentionDeficitHyperactivityDisorder110htm $\underline{1 . h t m}$ 
Newacheck, P.W., \& Taylor, W.R. (1992). Childhood chronic illness: prevalence, severity and impact. American Journal of Public Health, 82, 364-371.

Newacheck, P., McManus, M., \& Fox, H. (2000). Access to health care for children with special health care needs. Pediatrics, 105(4), 760-766.

Newacheck, P.W., Huang, Y.Y., \& Wright, K.K. (2002). Racial and ethnic disparities in access to care for children with special health care needs. Ambulatory Pediatrics, 2(4), 247-254.

Newacheck, P.W., \& Kim, S.E. (2005). A national profile of health care utilization and expenditures for children with special health care needs. Archives of Pediatric Adolescent Medicine, 159, 10-17.

Newacheck, P.W., Rising, J.P., \& Kim, S.E. (2006). Children at risk for special health care needs. Pediatrics, 118, 334-342.

Newacheck, P.W., Kim, S.E., Blumberg, S.J., \& Rising, J.P. (2008). Who is at risk for special health care needs: findings from the National Survey of Children's Health. Pediatrics, 122, 347-359.

Ngui, E.M., \& Flores, G. (2006). Satisfaction with care and ease of using health care services among parents of Children with Special Health Care Needs: the roles of race/ethnicity, insurance, language, and adequacy of family-centered care Pediatrics, 117, 1184-1196.

Palfrey, J.S., Sofis, L.A., Davidson, E.J., Liu, J., Freeman, L., \& Ganz, M.L. (2004). The pediatric alliance for coordinated care: evaluation for a medical home model. Pediatrics, 113(5), 1507-1516. 
Perrin, J.M. (2002). Health services research for children with disabilities. Milbank Quarterly, 80, 303-324.

Porterfield, S.L., \& McBride, T.D., (2007). The effect of poverty and caregiver education on perceived need and access to health services among children with special health care needs. American Journal of Public Health, 97(2), 323-329.

Roberts, R.N., Behl, D, \& Akers, A.L. (2004). Building a system of care for children with special health care needs. Infants and Young Children, 17(3), 213-222.

Ross, W.J., Chan, E., Harris, S.K., Goldman, S.J., Rappaport, L.A. (2011). PediatricianPsychiatrist Collaboration to Care for Children with Attention Deficit Hyperactivity Disorder, Depression, and Anxiety. Clinical Pediatrics, 50 (1), 3743.

Shenkman E., Wu, S., Nackashi, J., \& Sherman, J. (2003). Managed care organizational characteristics and health care use among children with special health care needs. Health Services Research, 38(6), 1599-1624.

Stein R.E. \& Jessop, D.J. (1991). Long-term mental health effects of a pediatric home care program. Pediatrics, 88(3), 490-496.

Stein, R.E.K., \& Johnson Silver, E. (2005). Are rates of functional limitations associated with access to care? A state-level analysis of the National Survey of Children with Special Health Care Needs. Maternal and Child Health Journal, 9S (2), S33-S39.

Strickland, B., McPherson, M., Weissman, G., van Dyck, P., Huang, Z.J., \& Newacheck, P. (2004). Access to the medical home; results of the national survey of children with special health care needs. Pediatrics, 113(5), 1485-1492. 
Tippy, K., Meyer, K., Aronson, R., \& Wall, T. (2005). Characteristics of coordinated ongoing comprehensive care within a medical home in Maine. Maternal and Child Health Journal, 9(S2), S13-S21.

Trochim,W.M.K., \& Donnelly, J.P. (2007). The research methods knowledge base (3rd ed.). Mason, $\mathrm{OH}$ : Thomson.

Tucker C., Casady R. J., \& Lepkowski, J. M. (1993). A hierarchy of list-assisted stratified telephone sample design options. Retrieved from http://www.amstat.org/sections/srms/proceedings/papers/1993_167.pdf

Turnock, Bernard J. (2004). Public health: What it is and how it works. Jones and Bartlett Publishers, Inc., Sudbury, MA.

Van Dyck, P.C., Kogan, M.D., McPherson, M.G., Weissman, G.R., \& Newacheck, P.W. (2004). Prevalence and characteristics of children with special health care needs. Archives of Pediatric and Adolescent Medicine, 158, 884-890.

Weller, W.E., Minkovitz, C.S., \& Anderson, G.F., (2003). Utilization of medical and health related services among school-age children and adolescents with special health care needs (1994 National Health Interview Survey on Disability [NHIS-D] Baseline Data). Pediatrics, 112(3), 593-603.

Witt, W.K., \& Riley, J.A. (2003). Mental health services use among school-aged children with disabilities: the role of socio-demographics, functional limitations, family burdens, and care coordination. Health Services Research, 38(6), 14411466. 


\author{
Curriculum Vitae \\ Madeline Marti-Morales \\ (787) 447-6076 \\ madelinemartiphd@gmail.com
}

\title{
EDUCATION
}

May 2011

PhD in Public Health with Specialization in Epidemiology Walden University

Minneapolis, Minnesota

June 2001

Master in Science in Epidemiology (MS)

University of Puerto Rico (UPR)

Medical Sciences Campus, San Juan, PR

May 1996

Bachelor in Biology with specialization in Microbiology (BS)

Minor in Business Administration - Accounting

Magna Cum Laude

University of Puerto Rico (UPR), Humacao, PR

SKILLS \& ABILITIES Knowledge, skills and experience in research design, methodology, multivariate and survival data analysis and reporting.

Spanish and English languages

Knowledge and skills in computer information systems, including Microsoft programs: Word, Excel, Power Point. Knowledge and skills in statistical analysis software, including the Statistical Package for Social Sciences (SPSS), EpiInfo and STATA.

Experience in literature review and electronic communication (e-mail).

\section{PROFESSIONAL EXPERIENCE}

May 2002- Present

\section{Epidemiologist}

Puerto Rico Department of Health

Section of Services to Children with Special Health Care Needs

Duties:

- Design, development and implementation of epidemiological research studies. This includes the development of research design protocols, statistical data analysis, methodology and reporting. 
- Design, development and implementation of the fiveyear Title $\mathrm{V}$ needs assessments for the Children with Special Health Care Needs (CSHCN) population to identify needs, establish priorities and develop action plans.

- Collection, management and analysis of data for health indicators.

- Projection of grant performance measures.

- Provide data to guide the implementation of strategic and action plans to improve the health services system.

- Development of mechanisms to gather information from multiple data sources, including government agencies, health insurance companies, health programs, private agencies, among others.

- Participation in the development and defense of the Title V federal block grant.

- Participation in the planning and implementation of plans with goals, objectives, strategies, resources and measurable indicators.

- Design, development and maintenance of primary and secondary databases.

- Development of professional reports with tables and graphical representations.

- Preparation of oral presentations.

- Search and critically review of peer-reviewed research publications and related scientific information.

- Participation in meetings to discuss the progress of action plans.

- Participation in the Title $\mathrm{V}$ annual block grant review meetings.

- Participation in state and national conferences, seminars and trainings in Epidemiology, data analysis, time trend analysis, need assessments, etc.

Feb. 2000-April 2002 Data Management and Analysis Director

Center for Research and Sociomedical Evaluation (CIES)

University of Puerto Rico, Medical Sciences Campus

Duties:

- Design and evaluation of questionnaires to be used in survey data collection.

- Bench testing and quality control testing of data collection tools.

- Design of databases, variable recoding, statistical analysis, and reporting. 
- Use of SAS program for complex statistical data analysis.

- Preparation of codebooks with variable frequencies and codes.

- Preparation of charts, graphs and flowcharts using computer programs.

- Preparation of reports with summary results and conclusions.

- Participation in conference calls, seminars and meetings.

Aug. 1998-May 1999 Teaching Assistant

Department of Epidemiology and Biostatistics

University of Puerto Rico, Medical Sciences Campus

Duties:

- Supervision of users in the Epidemiology Department's Computer Room.

- Installation of software and monitoring of the good functioning of information systems.

Aug. 1996-May 1997 Teaching Assistant in Biology Laboratories State University of New York (SUNY) at Albany Duties:

- Teaching of biology laboratory sessions to bachelor students (two laboratories per week).

- Evaluation and grading of students.

\section{PARTICIPATION IN CONFERENCES, TRAININGS AND ASSOCIATIONS}

October 2010 Participation in the World Statistics Day, San Juan, PR

August 2010 Title V Maternal and Child Health Federal Block Grant Review Meeting, HRSA Office, Federal Building, San Juan, Puerto Rico

August 2009 Title V Maternal and Child Health Federal Block Grant Review Meeting, HRSA Office, Federal Building, San Juan, Puerto Rico

March 2009 Annual Conference of the Association of Maternal and Child Health Programs, Launching MCH Opportunities for a New Era, Washington, DC

December 2007 Time Trend Analysis Training \& MCH Epidemiology Conference, Sponsored by the Centers for Disease Control and Prevention (CDC) and the Maternal and Child Health Bureau, Atlanta, Georgia 
October 2007 First Prevention Summit of the PR Department of Health and the Medical Sciences Campus of the University of Puerto Rico, New Prevention Approaches at the Community Level, PR Convention Center, San Juan, Puerto Rico

August 2007 Title V Maternal and Child Health federal block grant review meeting HRSA Office, Federal Building, San Juan, Puerto Rico

March 2007 Annual Conference of the Association of Maternal and Child Health Programs, Healthy Communities, Arlington, Virginia

August 2006 Training on the Basic Audit Concepts and Techniques through the Audit Process, Office of Inspector General, Office of Audit Services, San Antonio, Texas

May 2006

Annual Conference of the Association of Maternal and Child Health Programs, Early Childhood: Building the Foundation for Lifelong Health, Arlington, Virginia

May 2005 Annual Conference of the Association of Maternal and Child, Health Programs Delivering Results: Improving Pregnancy and Birth, Washington, DC.

June 2005 Training on Maternal and Child Health Epidemiology, Sponsored by the Maternal and Child Bureau, Health Resources and Services Administration (HRSA), Centers for Disease and Control Prevention (CDC) and the Association of Maternal and Child Health Programs, Boston, Massachusetts

August 2005 Title V Maternal and Child Health federal block grant review meeting, Jacob Javits Federal Building, New York City, New York

1995-1996 Participant of the Minority Access to Research Careers Program (MARC), University of Puerto Rico, Humacao Campus

October 1995 Poster presentation at the MARC Convention, Washington, DC Minority Access to Research Careers Program, University of Puerto Rico, Humacao Campus

1993-1996 Member of the Microbiology Student Chapter, University of Puerto Rico, Humacao Campus

1991-1996 Member of the Honor Student Program, University of Puerto Rico, Humacao Campus

REFERENCES Available upon request. 